In press: Assessment

\title{
Factor Structure and Construct Validity of the Proposed Specifiers for Conduct Disorder (PSCD) Scale in Chinese Adolescents
}

\author{
Jie Luo \\ Guizhou Normal University \\ Meng-cheng Wang \\ Guangzhou University \\ Craig S. Neumann \\ University of North Texas \\ Robert D. Hare \\ Darkstone Research Group \\ University of British Columbia \\ Randall T. Salekin \\ University of Alabama
}

Correspondence concerning this article should be addressed to Randall T. Salekin, PhD. Department of Psychology, University of Alabama: email: rsalekin @ ua.edu. Or to Mengcheng Wang, PhD. Department of Psychology, Guangzhou University: email: wmcheng@126.com

2020 Assessment, Sage. This paper is not the copy of record and may not exactly replicate the final authoritative version of the article. Please do not copy or cite without author permission. The final article will be available upon publication via its doi: 


\begin{abstract}
The Proposed Specifiers for Conduct Disorder (PSCD) Scale is a new measure to assess psychopathic traits and symptoms of CD in children and adolescents. The current study examined the psychometric properties of the self-report version of the PSCD in a sample of community adolescents in mainland China $(N=1,683$; mean age $=13.60, S D=1.14 ; 54.1 \%$ boys). The new instrument showed good internal consistency (alpha) for the 24-item total scale and good mean inter-item correlations for each of the 6-item subscales. Confirmatory factor analyses (CFAs) were conducted on all 24 items, and also a subset of 13 items that demonstrated strong item-level reliabilities. Using all 24 items, CFA results supported a fourfactor bifactor model indicating the total score reflects a broad syndrome with four factors. The four factors included Grandiose-Manipulative traits (GM traits), Callous Unemotional traits (CU traits), Daring Impulsive traits (DI traits), and Conduct Disorder (CD traits). The 13-item CFA results provided further support for a four-factor conceptualization of the PSCD and evidence of strong measurement invariance across gender. Finally, the PSCD exhibited the expected relations with other psychopathy measures, anxiety and depression, and aggression, supporting the PSCD scores convergent, discriminant, and criterion related validity. The findings provide preliminary evidence for the four-factor structure of the PSCD and support for the utility of the self-report PSCD for measuring psychopathic traits and CD in Chinese adolescents.
\end{abstract}

Keywords: psychopathy, PSCD, conduct disorder (CD), GM traits, CU traits, DI traits, Chinese adolescents 
Psychopathy is a multidimensional construct that contains interpersonal, affective, behavioral and antisocial characteristics exhibited in both adults (Hare, 2003) and children (Salekin, 2017). Interpersonal traits include such characteristics as grandiosity, manipulation, and deceitfulness. Affective traits include such traits as callousness, lack of empathy, and shallow affect. Lifestyle characteristics include impulsivity, need for stimulation, and irresponsibility. Finally, antisocial features include such behaviors as overt aggression and antisocial conduct. This general factor structure has been replicated numerous times in adult samples as well as other age bands including adolescent and child samples (Frick, Bodin, \& Barry, 2000; Hare, 2003; Hare \& Neumann, 2008; Neumann, Hare, \& Newman, 2007).

This paper focuses on the Proposed Specifiers for Conduct Disorder (PSCD, Salekin \& Hare, 2016; Salekin, 2017) scale which has similar proposed structure as the one noted above with grandiose-manipulative (GM) traits, callous-unemotional (CU) traits, daring-impulsive (DI) traits, and Conduct Disorder (CD). The PSCD is designed for children and adolescents to advance our understanding of the psychopathy especially as it relates to Conduct Disorder as well as in terms of better understanding the etiology and treatment of the various types of youth with CD. The inclusion of multiple dimensions is key, because each dimension could offer quite unique and important clinical information as it pertains to $\mathrm{CD}$. For instance, youth with GM traits could potentially exhibit greater feelings of superiority over others which could propel conduct problems (CD). Those youth with CU traits may lack feelings of remorse or guilt for actions that hurt others which could impact the extent to which they engage in conduct problems (CD). And, those individuals with DI traits may exhibit daring and reckless behavior that consequently influences the degree to which they partake in conduct problems $(\mathrm{CD})$.

It should be noted that extensive research on this topic has demonstrated that psychopathic traits are multidimensional and can be indexed in childhood and adolescence 
(e.g., Andershed et al., 2018; Forth, Kosson, \& Hare, 2006; Gillen, MacDougall, Forth, Barry, \& Salekin, 2019; Kotler \& McMahon, 2010; Muñoz \& Frick, 2007; Salekin \& Lynam, 2010; Salekin, 2017; Vitacco, Rogers, \& Neumann, 2003). Moreover, research has shown that psychopathy in youthful samples is linked to severe conduct problems, long-lasting psychosocial problems, delinquency, behavior maladjustment, as well as to various forms of aggressive behavior, including relational aggression, reactive aggression, and proactive aggression (e.g., Colins et al., 2018; Forth \& Book, 2010; Frick, Ray, Thornton, \& Kahn, 2014; Salekin \& Lynam, 2010; Vitacco, Neumann, Caldwell, Leistico, \& Van Rybroek, 2006; Wang, Deng, Armour, Bi, \& Zeng, 2015). In addition, psychopathic traits have shown moderate stability and invariance across significant time spans (e.g., Andershed, 2010; Frick, Kimonis, Dandreaux, \& Farell, 2003; Lynam, Caspi, Moffitt, Loeber, \& Stouthamer-Loeber, 2007; Muñoz \& Frick, 2007; Waller, Gardner, Hyde, Shaw, Dishion, \& Wilson, 2012) indicating that the same underlying construct is represented across development (Neumann, Wampler, Taylor, Blonigen, \& Iacono, 2011).

Studies on the topic of child and adolescent psychopathy have significantly advanced our understanding over the past decade, although as has been noted, many questions still remain (see Salekin, 2017). Being able to reliably and validly measure psychopathic traits in these age groups is of clinical and scientific interest because it can shed light onto the different pathways that lead to conduct disorder (CD) and severe antisocial behavior, provide opportunity for early interventions, and ultimately, increase our understanding of the etiology of this socially destructive personality disorder which fully manifests in adulthood (e.g., Salekin, 2017; van Baardewijk, Andershed, Stegge, Nilsson, Scholte, \& Vermeiren, 2010). To date, studies of psychopathic traits in youth have yielded remarkable similarities to those in adults in terms of structure, stability, and relations to conduct problems and aggression, and cognitive and emotional functioning (Andershed et al., 2018; Burke, Loeber, \& Lahey, 
2007; Colins et al., 2018; Somma et al., 2018; Kotler \& McMahon, 2005; Lynam \& Gudonis, 2005; Neumann, Kosson, Forth, Hare, 2006). Therefore, it is important to study psychopathy among adolescents in order to describe the manifestations of psychopathic traits in this age group, to identify the potential precursors and transitions to adult psychopathy, and to further understand the development of severe antisocial behavior (e.g., Colins et al., 2018; Fanti et al., 2018; Farrington, 2005; Rutter, 2005; Salekin \& Lynam, 2010, 2017; Somma et al., 2018).

Despite the importance of examining psychopathic traits in youth, recent studies using child and adolescent samples now tend to examine only one component of psychopathy, namely, callous unemotional traits. However, strong evidence of the multifarious nature of psychopathy (Andershed et al., 2018; Colins et al., 2018; Frick et al., 2000; Harpur, Hare, \& Hakstian, 1989; Muñoz \& Frick, 2007; Neumann, Hare, \& Pardini, 2015; Salekin et al., 2006), and initial studies showing a combination of psychopathic traits are highly predictive of CD indicate that research efforts are still needed to account for the broader nature of child psychopathic traits (e.g., Salekin, Andershed, Batky, \& Bontemps, 2018). Multicomponent psychopathy research studies will provide a better understanding of the etiology of the condition as well as the different ways in which CD can manifest in youth. Such investigations require the use of a reliable and valid measure of psychopathic traits in adolescents. The present study aimed to validate a newly developed instrument, the Proposed Specifiers for Conduct Disorder scale (PSCD; Salekin \& Hare, 2016), designed to cover a full complement of psychopathic traits in children as well as different manifestations of CD.

In this study, we focus on the self-report version of the PSCD in order to test its psychometric properties. While we focus on the PSCD self-report in this investigation, which oftentimes can be the easiest to collect in school and community studies, it should be noted that other sources of reporting, such as those from teachers, parents, and/or peers will also be 
informative. Indeed, parent report of psychopathy traits can be useful in understanding young individuals with conduct problems from a different perspective and in some studies has resulted in larger effects for delinquency and treatment outcome (see Falkenbach, Poythress, \& Heide, 2003; Lopez-Romero et al., 2019; Muñoz \& Frick, 2007; White, Cruise, \& Frick, 2009). Although the purpose of this study is to test the self-report version of the PSCD, because it can be so useful in school and community studies, it should be recognized that parent and teacher report are also valuable and that the combination of measures can also be very beneficial for a fuller understanding of personality traits in children (see White et al., 2009).

\section{Youth Psychopathy Measures}

To date, three widely utilized youth psychopathy instruments are the Psychopathy Checklist: Youth Version (PCL: YV; Forth, Kosson \& Hare, 2003), the Antisocial Process Screening Device (APSD; Frick \& Hare, 2001), and the Youth Psychopathic Traits Inventory (YPI; Andershed, Kerr, Stattin, \& Levander, 2002) and its short form (YPI-S; van Baardewijk et al., 2010). The PCL and its revised version (PCL-R; Hare, 2003) were designed for the systematic measurement of adult psychopathy. In the late 1980s, Forth and colleagues adapted the PCL for use with adolescents in correctional facilities, and this marked the beginning of systematic, empirical work with youth (Forth, Hart, \& Hare, 1990). The PCL: YV primarily has been successfully used in incarcerated samples of adolescents (aged 12- to 18- years) and utilizes a 60-90 minutes semi-structured interview and a file review. It is thus a comprehensive, but a time-consuming assessment process, and therefore is not easily accommodated in large-scale community studies.

The APSD (Frick \& Hare, 2001) is a 20-item measure purportedly based on the PCL-R (Hare, 2003) items. The first version of the APSD was a parent and teacher rated assessment of both personality traits and behavior in children. The 20-items of the APSD have also been 
modified to create a self-report version for use with adolescents (APSD-SR; Caputo, Frick, \& Brodsky, 1999; Goodwin, Sellbom, \& Salekin, 2015; Loney, Frick, Clements, Ellis, \& Kerlin, 2003; Wang et al., 2015). Although the APSD and APSD-SR are reportedly based on the PCL, there is a lack of complete agreement between the conceptually similar items of the APSD and the PCL instruments (Dillard, Salekin, Barker, \& Grimes, 2013; Falkenbach et al., 2002). Dillard et al. (2013) showed that there is not a parallel item for each of the PCL-R and APSD items (5 items on the APSD have no parallel item on the PCL; e.g., "You tease or make fun of other people"). Moreover, the factor structure for the APSD differs from the PCL and PCL-YV (Dillard et al., 2013). Specifically, the two-factor structure of the APSD does not map well onto the adult PCL-R and PCL: YV factor structure (e.g., Frick, O'Brien, Wootton, \& McBurnett, 1994; Pechorro, Maroco, Poiares, \& Vieira, 2013). To further complicate issues, the labels for the Frick et al. (1994) factor structure do not perfectly align with the highest loading items on the respective scales. For instance, the top three highest loading items for the Impulsive/Conduct Problems scale could be viewed as interpersonal (grandiose-manipulative) items (i.e., "brags about accomplishments," "becomes angry when corrected," "thinks he/she is more important than others"). Similarly, the top loading item for the callous unemotional (CU) scale ("concerned about school work") is non-pathognomonic and may pertain to a variety of different psychiatric conditions (e.g., depression, anxiety). In addition, the CU scale contains items that many would consider to be grandiose-manipulative (GM) traits ("acts charming in ways that seem insincere," "uses or cons others," "lies easily and skillfully"). This means that some of the early work to support CU traits used to support the LPE specifier, was likely based on a mix of GM and CU traits. The three-factor model (e.g., Bijttebier \& Decoene, 2009; Frick et al., 2000; Vitacco et al., 2003) and four-factor solutions (e.g., Wang et al., 2015) offer an improvement in content, however, the CU scale still tends to suffer from low reliability estimates. Some of these problems led to the creation 
of the Inventory of Callous-Unemotional Traits (ICU; Frick, 2004) although this instrument only measures one component of psychopathy (e.g., Callous and Unemotional; CU) and has also been shown to evidence some problematic psychometric features (Latzman, Lilienfeld, Latzman, \& Clark, 2013; Ray, Frick, Thornton, Steinberg, \& Cauffman, 2016).

The YPI (Andershed et al., 2002), on the other hand, uses several items to map 10 core psychopathic trait domains. The YPI was also designed specifically for use with community adolescents (Andershed et al., 2002). This 50-item self-report instrument is based on the three-factor model of psychopathy and focuses on 10 out of the 13 psychopathic traits asserted by Cooke and Michie (2001) to be core features. For most studies, the full 50 items and lengthy (20 minutes) administration time may not be necessary. The YPI-S (van Baardewijk et al., 2010) is an 18-item shorten form of the YPI (Andershed et al., 2002), including three 6-item subscales: Grandiose-Manipulative (GM), Callous-Unemotional (CU), and Impulsive-Irresponsible (II). Studies have demonstrated that the psychometric properties of the YPI-S are adequate in youths (e.g., van Baardewijk et al., 2010; Wang, Colins, Deng, Andershed, Deng, \& Ye, 2017; Zwaanswijk, Veen, \& Vedder, 2017). The YPI presents itself as a "purely" personality trait measure that does not include overt antisociality, although Hare and colleagues (Hare, Neumann, Mokros, 2018; Neumann et al., 2015), and others (e.g., Lynam \& Miller, 2012; Miller \& Lynam, 2015), have shown that both covert (deceptive, callous use of others) and overt antisocial (poor behavioral controls, aggressive interactions) features are inherent aspects of the psychopathy construct.

Recently, the Child Problematic Traits Inventory (CPTI; Colins, Andershed, Frogner, Lopez-Romero, Veen, \& Andershed, 2014) was designed to assess psychopathic traits in terms of the three factors including Grandiose-Deceitful (GD), Callous-Unemotional (CU), and Impulsive-Need for Stimulation (INS) in early children from age 3 to 12 . The CPTI consists of 28 items that are rated by the preschool, kindergarten, or grade school teacher of a 
child. Studies have demonstrated that the psychometric properties of the CPTI are adequate both in teacher-rated (e.g., Colins, Fanti, Larsson, \& Andershed, 2017; López-Romero et al., 2018) and parent-rated scores (e.g., Luo et al., 2019; Somma, Andershed, Borroni, \& Fossati, 2016; Wang, Colins, Deng, Deng, Huang, \& Andershed, 2018).

In sum, although the aforementioned instruments are widely used for youth psychopathy, and emphasize three psychopathy dimensions (e.g., Grandiose-Manipulative, Callous-Unemotional, and Impulsive), a widely held view is that child and adolescent psychopathic traits are best represented by three component dimensions in conjunction with antisocial conduct or CD (Salekin, 2016a, 2017; Salekin \& Hare, 2016). Therefore, it will be helpful for investigators to examine the broader construct and its full set of component traits if we are to better understand CD. Based on item representativeness and content validity of the psychopathic traits, Salekin and Hare (2016) developed the PSCD.

\section{The Proposed Specifiers for Conduct Disorder (PSCD) Scale}

The PSCD is a 24-item measure with four 6-item subscales: Grandiose-Manipulative (GM), Callous-Uncaring (CU), Daring-Impulsive (DI), and Conduct Disorder (CD). Within the PSCD interpersonal domain, items measure grandiosity, superficial charm, manipulation, and deceit. The affective component includes items intended to assess callousness, uncaring shallow affect, and disregard for others. Within the lifestyle component, items include daringness, thrill seeking, recklessness, and irresponsibility. In the conduct disorder domain, items measure aggression, destruction of property, theft, as well as antisocial behavior and other conduct problems.

There are early indications that the PSCD may be a useful measure for its intended purpose. In a study of 2,229 Spanish children aged 3 to 6, López-Romero et al. (2019) obtained support for both a three- and a four-factor structure for the parent version of the PSCD. They also obtained the expected convergent/divergent associations with an alternative 
measure of psychopathic traits (CPTI; Colins et al., 2014), measures of fearlessness, conduct problems, reactive and proactive aggression, ADHD and ODD symptoms, and social competence skills. To the best of our knowledge, however, there are no published studies on the psychometric and structural properties of the PSCD with adolescents.

\section{The Current Study}

The purpose of the present study was to examine the factor structure and psychometric properties of the self-report version of the PSCD in Mainland Chinese adolescents. Selfreport can be useful and thus requires psychometric investigation, but, it should be recognized that examining personality traits can benefit from the consideration of other sources of information such as peer, parent, and teacher ratings (Falkenbach et al., 2003; Muñoz \& Frick, 2007; White et al., 2009). With regard to hypotheses for the current study, we did not expect gender differences. This hypothesis was based on past research which has generally shown psychopathy to be invariant across gender with respect to factor structure and general correlates (see Forth et al., 2003; Kosson et al., 2013; Tuvblad, Fanti, Andershed, Colins, \& Larsson, 2017). We also did not expect cultural differences based on what has been found in past research (e.g., Forth et al., 2003). This hypothesis aligns with other cross cultural research which has generally shown psychopathy to be invariant across culture (Forth et al., 2003; Verona, Sadeh, \& Javdani, 2010; Somma et al., 2018).

For the full set of 24 PSCD items, a series of confirmatory factor analyses (CFAs) were conducted to examine and compare competing models of the PSCD (i.e., a one-factor model, the original four-factor solution, a second-order model, and a bifactor model). The first model (M1) was a one-factor model, with all 24-items specified to load on to a unidimensional (PSCD) factor. The M1 model was not expected to fit well, given the evidence of the multidimensional nature of psychopathy. The second model (M2) represented the original fourfactor model (Salekin \& Hare, 2016; Salekin, 2017), which included four (6-item) factors to 
represent the PSCD subscales (i.e., GM, CU, DI, and CD, respectively), and the factors were allowed to freely correlate. We hypothesized that the four correlated factors model (M2) would show acceptable fit. A third model (M3) reflected a second-order solution that specified the lower-order factors (e.g., GM, CU, DI and CD) to load on a higher-order factor to represent a broad (PSCD-based) psychopathy syndrome. For the final 24-item model (M4), a four-factor bifactor model was employed. In this model, all items are set to load onto a general factor, and also, items are set to load onto their respective content factors (GM, CU, DI, CD), which are referred to as specific or group factors. The bifactor model provides another possible representation of the broad syndrome, and it is an ideal model for mathematically representing a total scale score (e.g., the full 24-item PSCD scale; although see Bonifay, Lane, \& Reise, 2017). Finally, we also conducted additional latent variable model analyses to find the most robust set of items that best represented the four psychopathy domains (GM, CD, DI, and CD). This type of correlated factors model has been successfully employed in psychopathy research in the past and provides a good representation of the domains involved in psychopathic personality. Such models allow investigators to determine if the individual factors have unique and potentially differential associations with critical external correlates (Hoppenbrouwers, Neumann, Lewis, \& Johansson, 2015).

To determine the internal consistency of the PSCD items, we computed alpha coefficients, coefficient omega, and mean inter-item correlations (MICs). The latter two (coefficient omega and MIC) are not affected by the number of items per scale. In-line with model-based test theory (Embretson \& Hershberger, 1999), we counted on the reliability analyses to help identify a subset of items that best statistically captured child psychopathic features. Given that some items within a measure contain significantly more information involving item discrimination and extremity/threshold parameters (e.g., Sharp, Steinberg, Temple, \& Newlin, 2014; Walton, Roberts, Krueger, Blonigen, \& Hicks, 2008), we expected 
to find a set of PSCD items that would optimally capture the four psychopathy domains. We then tested whether the items with significant parametric information demonstrated measurement invariance across girls and boys.

Using a multitrait-multimethod matrix, we then tested the relations between the psychopathy dimensions (e.g., GM, CU, and DI) to determine if the PSCD subscales would demonstrate adequate convergent and discriminant validity. Convergent validity of the PSCD was tested by examining the relation between the PSCD scores and other psychopathic trait or component measures (e.g., APSD, Frick \& Hare, 2001; ICU, Frick, 2004; YPI, Andershed et al., 2002). The discriminant validity of the PSCD was examined through calculating its association with anxiety and depression (i.e., GAD; Spitzer, Kroenke, Williams, \& Löwe, 2006; PHQ; Kroenke, Spitzer, \& Williams, 2001). Finally, the criteria validity of the PSCD was assessed by computing Pearson product-moment correlations with conceptually relevant external criteria variables including general aggression, rule-breaking, reactive aggression, and proactive aggression (e.g., YSR; Achenbach, 1991; RPQ; Raine et al., 2006). Given the previous studies on the relation between adult psychopathy and aggression, we anticipated that psychopathic traits would positively correlate with children's aggressive behavior and conduct problems (e.g., Frick et al., 2014; Salekin, 2008; van Baardewijk, Stegge, Bushman, \& Vermeiren, 2009; Wang et al., 2015).

\section{Method}

\section{Participants}

The data for the present study was collected from three middle schools in Guangdong, China. All the three samples were employed to conduct the confirmatory factor analyses. The convergent and criterion validity was only conducted in the second sample and the discriminant validity was only conducted in the third sample. The individual samples have the following characteristics: Sample One: A total of 644 participants (56.0\% male; 11-14 
years old; mean age $=12.52, S D=.62$ ), were recruited from one middle school, consisting of $367(57.0 \%)$ 7th graders and $276(42.9 \%)$ 8th graders, among which $98.0 \%$ were Han. Sample Two: A total of 476 participants (52.9\% boys; $12-17$ years old; mean age $=14.67$; SD $=.87)$ were recruited within one middle school, including $236(49.6 \%) 7$ th graders and 240 (50.4\%) 8th graders, among which 98.5\% were Han. Sample three: The third sample included a total of 563 8th graders $(50.8 \%$ boys; $13-16$ years old; mean age $=13.97 ; \mathrm{SD}=$ .57) recruited within two middle schools, among which 95.7\% were Han.

\section{Procedure}

The appropriate IRB approval was sought and obtained from the Guangzhou University and local school board. Following IRB approval, informed consent was obtained from the parents (or legal guardians) prior to the administration of any self-report questionnaires. Participants were informed that the study was voluntary and they could discontinue at any time. In addition, participants were informed that their answers would remain anonymous and were invited to ask questions regarding the investigation. Research assistants were available to answer participant questions during the study. Participants completed the survey lasting approximately 35 minutes in quiet classroom conditions.

\section{Measures}

\section{Proposed Specifiers for Conduct Disorder Scale (PSCD; Salekin \& Hare, 2016)}

The PSCD (Salekin \& Hare, 2016) is a 24-item psychopathic traits measure designed for administration in youths, consists of four subscales including Grandiose-Manipulative (GM; 6 items), Callous-Uncaring (CU; 6 items), Daring-Impulsive (DI; 6 items), and Conduct Disorder (CD; 6 items). Each item was rated on a 3-point Likert scale $(0=$ not true, $1=$ sometimes true, $2=$ true). All three samples completed the PSCD. The Chinese version of the PSCD was translated into Chinese (Mandarin) by the second author (native Chinese speaker) and was back translated into English by bilingual speaker. The final version was further 
discussed by the abovementioned translators and the fifth author (the original author R. T.

Salekin), until they reached an agreement.

\section{Antisocial Process Screening Device-Self-Report Version (APSD-SR)}

The APSD-SR (Frick \& Hare, 2001) is a 20-item antisocial behavior and psychopathic traits scale designed for administration with adolescents. Each item was scored on a 3 points Likert-type scale, ranging from 0 (not at all true) to 2 (definitely true). The original APSDSR comprised of Callous-Unemotional (CU), Narcissistic (NAR) and Impulsive (IMP) subscales (e.g., Frick et al., 2000; Vitacco et al., 2003), despite a new factor pertaining to Asocial behavior (ASO) subscale was found within the Chinese version of APSD-SR (Wang et al., 2015). In the current study, coefficient $\alpha$ s for the CU, NAR, IMP, and ASO subscale were $.41(\mathrm{MIC}=.15), .45(\mathrm{MIC}=.12), .55(\mathrm{MIC}=.17), .14(\mathrm{MIC}=.05)$, respectively. Only sample two completed this scale. Although these reliability coefficients are lower than expected, the APSD was nonetheless used in the current study to compare with the other psychopathy scales.

\section{Inventory of Callous-Unemotional Traits-11 (ICU-11)}

The ICU-11 (Wang et al., 2017) is a 11-item short form of the original ICU (Frick, 2004), designed to measure Callousness (6-item) and Uncaring factor (5-item). Each item was rated on a 4 points Likert-type scale, ranging from 1 (not at all true) to 4 (definitely true). The Chinese short version of ICU has been validated (Wang et al., 2017) and used in the Chinese population (Wang et al., 2019; Zhang et al., 2019). In the present study, alpha coefficients for the Callousness and Uncaring factor were .64 $(\mathrm{MIC}=.24)$ and $.66(\mathrm{MIC}=$ .28), respectively. Only sample two completed this measurement.

\section{Youth Psychopathic Traits Inventory-Short Version (YPI-S)}

The YPI-S (van Baardewijk et al., 2010) is an 18-item self-report shorter version of the original YPI (Andershed et al., 2002), designed to assess three higher order dimensions 
(including 6-item in each subscale): Grandiose-Manipulative (GM), Callous-Unemotional (CU), and Impulsive-Irresponsible (II). Each item was scored on a 4-point Likert scale in which 1 indicated does not apply at all and 4 indicated applies very well. The Chinese version of YPI-S has been validated with Chinese adolescents (Wang et al., 2017). In the current study, alpha coefficients for the GM, CU, and II subscale were $.71(\mathrm{MIC}=.32), .57$ $(\mathrm{MIC}=.18)$, and $.66(\mathrm{MIC}=.23)$, respectively. Only sample two completed this scale.

\section{Youth Self-Report (YSR)}

Two factors within the YSR (Achenbach, 1991), Rule-Breaking behavior (RB, 13-item) and Aggressive behavior (AGG, 20-item), were used in the current study. Each item was answered on a 3-point Likert scale, ranging from 0 (never true) to 2 (always true). The Chinese version of the YSR has been validated and used in the Chinese population (Leung et al., 2006; Wang et al., 2015; Wang et al., 2017). In the present study, the Cronbach's alphas for the RB and AGG factor were $.68(\mathrm{MIC}=.18)$ and $.82(\mathrm{MIC}=.19)$, respectively. Only sample two completed this measure.

\section{Reactive-Proactive Aggression Questionnaire-11 (RPQ-11)}

The RPQ-11 (Liu, You, Mai, Gao, \& Wang, 2019) is an 11-item self-report shortened version of the original RPQ (Raine et al., 2006), designed to measure reactive (5 items) and proactive aggression (6 items) in children and adolescents. In the self-report version, participants are asked about reasons of their aggressive behaviors, and questions are not restricted to events which have occurred in the past few months. Each item was rated on a 3 points Likert-type scale ( $O=$ never, $1=$ sometimes, $2=$ often $)$. The Chinese version of RPQ has been validated (Fung, Raine \& Gao, 2009) and used in Chinese samples (Gao, Zhang, \& Fung, 2015; Wang et al., 2015). In the current study, coefficient $\alpha$ s for the reactive and proactive aggression were.72 $(\mathrm{MIC}=.34)$ and $.70(\mathrm{MIC}=.28)$, respectively. Only sample two completed this scale. 


\section{Generalized Anxiety Disorder-7 (GAD-7)}

The GAD-7 (Spitzer et al., 2006) is a brief 7-item self-report scale to identify generalized anxiety disorder (GAD). This brief tool was developed that asked participants how often, during the last 2 weeks, they were bothered by each symptom. Each item was rated on a 4 -point Likert scale $(0=$ not at all, $1=$ several days, $2=$ more than half the days, and $3=$ nearly every day). In the present study, alpha coefficient for the GAD-7 was .85 $(\mathrm{MIC}=.45)$. Only sample three completed this measure.

\section{Patient Health Questionnaire-9 (PHQ-9)}

The PHQ-9 (Kroenke et al., 2001) is an abbreviated depression diagnostic and severity measure. This measure has comparable sensitivity and specificity and consists of the actual nine criteria on which the diagnosis of DSM-IV depressive disorders is based (Kroenke et al., 2001). Each item was answered on a 4-point Likert scale, ranging from 0 (not at all) to 3 (nearly every day). In the current study, the Cronbach's alpha for the PHQ-9 was .81 (MIC = .32). Only sample three completed this scale.

\section{Data Analysis}

First, descriptive statistics for all scales were performed with SPSS 25.0 (IBM Corp., 2019). Next, a set of CFAs were conducted by means of Mplus 7.0 (Muthén \& Muthén, 1998-2015) to examine and compare the four proposed factor models of the PSCD scores. Given that the values of the skewness and kurtosis for some items were beyond -1 or +1 , and that the PSCD assessment was rated on a 3 points Likert-type scale $(0=$ not true, $1=$ sometimes true, 2 = true), the robust weighted least squares with mean and variance adjustment (WLSMV) was used. This method is robust to non-normal and categorical data (Flora \& Curran, 2004). CFA fit indices included the CFI, TLI, and RMSEA. Following Hu and Bentler's (1999) suggestions, CFI and TLI values above .95, and RMSEA scores below 
.05 , indicate good fit, whereas CFI and TLI larger than .90, and RMSEA smaller than .08 suggest adequate model fit (Hu \& Bentler, 1999).

To evaluate the bifactor model, the coefficient omega hierarchical $\left(\omega_{H}\right)$, the omega hierarchical subscale $\left(\omega_{H S}\right)$, and the explained common variance $(\mathrm{ECV})$ were calculated using Mplus 7.0 (Muthén \& Muthén, 1998-2015). The $\omega_{H}$ reflects the proportion of variance in total scores which can be attributed to the general factor (Zinbarg, Yovel, Revelle, \& McDonald, 2006). The $\omega_{H S}$ indicates the reliability index of a factor after controlling for the variance of the general factor (Reise, Bonifay, \& Haviland, 2013). When $\omega_{H}$ is high (> .80), total scores can be considered essentially unidimensional, in the sense that the vast majority of reliable variance is attributable to a single common source, whereas a high $\omega_{H S}$ suggests that the vast majority of reliable variance is attributable to a specific factor rather than a general factor (Reise et al., 2013). Moreover, the value of ECV is the percent of common variance that is explained by the general factor and is considered a unidimensionality indicator (Rodriguez, Reise, \& Haviland, 2016). In contrast to $\omega_{H}$, the ECV does not increase when additional items are added to a measure and a high ECV implies that the general factor dominates the reliable variance. While we used the very stringent criteria of $\mathrm{Hu}$ and Bentler (1999), and the above mentioned criteria, researchers have suggested that these criteria may be too stringent for personality measures (Hopwood \& Donnellan, 2010) and argue for the consideration of other factors such as the convergent and discriminant validity of the measures.

Next, the internal consistency of the PSCD scores was examined using Cronbach's $\alpha$, McDonald's $\omega$, and MIC. These reliability estimates were considered against some common benchmarks for context. Specifically, Cicchetti and Sparrow (1990) note that alphas at .70.79 are "fair," .80-.89 are "good," and .90 and above are "excellent" for clinical significance. These benchmarks cannot easily be used for short item length scales because short item scale 
length affects alpha. For McDonald's $\omega$, the same benchmarks provided by Cicchetti and Sparrow (1990) can be used to interpret reliability estimates, but again the same cautions pertain for scales with a small number of items. Clark and Watson (1995) provide guidelines for MIC values suggesting that acceptable correlation coefficients range from .15 to .50 . Following Cicchetti (1994), Clark and Watson (1995) and Tavakol and Dennick (2011), alpha coefficients were expected to be good for total scores and modest-to-low for subscales due to the low number of items in subscales. For the follow-up model analyses, we identified PSCD items within each scale that had moderate to strong (corrected) item-to-total correlations ( .30 or higher). The three best respective items within the GM, CU, and DI scales were selected, along with the four CD items that represent each of the subtypes of CD delineated in the DSM-5 (Aggression to People and Animals, Destruction of Property, Deceitfulness and Theft, and Serious Violation of Rules).

Finally, Pearson product moment correlations coefficients were examined between the PSCD scores and alternative psychopathy measures (i.e., APSD, YPI) and component measures (i.e., ICU), mental disorders (i.e., Generalized Anxiety Disorder, and Depression), and children's aggressive behavior (i.e., Rule-Breaking behavior, Aggressive behavior, Reactive Aggression, and Proactive Aggression). According to Hemphill (2003), the correlation coefficients $\leq .10$ indicate weak; .20 to .29 suggest moderate; and $\geq .30$ indicate strong. All analyses were conducted by SPSS 25.0 unless otherwise specified.

\section{Results}

\section{Descriptive Statistics}

Descriptive statistics of the PSCD scores on the total sample are presented in Table 1. As can be seen, there was a reasonable amount of dispersion in the study variables. The PSCD had a mean score of 13.33 and a SD of 6.09. The GM subscale had a mean of 4.18 with a SD of 2.12. CU traits had a mean of 1.91 with a SD of 1.76 , and DI traits evidenced a 
mean of 4.66 with an SD of 2.23. The CD scale of the PSCD had a mean of 2.58 and an SD of 2.37. Online supplemental Table 1 exhibits the descriptive statics for the complete panel of study variables.

\section{Factor Structure of the PSCD}

The 24-item model fit indices of the one-factor model (M1) were poor (WLSMV $\chi^{2}=$ 2915.81 $, d f=252, \mathrm{CFI}=.73, \mathrm{TLI}=.71, \mathrm{RMSEA}=.08)$. Similarly, the original four-factor model (M2) did not provide a satisfactory model fit $\left(\mathrm{WLSMV} \chi^{2}=2379.45, d f=246, \mathrm{CFI}=\right.$ $.79, \mathrm{TLI}=.74, \mathrm{RMSEA}=.07)$, as well as the second-order solution $\left(\mathrm{M} 3\right.$; WLSMV $\chi^{2}=$ 2358.01 $, d f=248, \mathrm{CFI}=.79, \mathrm{TLI}=.76, \mathrm{RMSEA}=.07)$, while the model fit indices of the bifactor model (M4) was generally acceptable (WLSMV $\chi^{2}=1222.91, d f=228, \mathrm{CFI}=.90$, $\mathrm{TLI}=.88, \mathrm{RMSEA}=.05)$, and the best model fit among the four models. Of note, the factor loading for item 17 (I like to live in the moment) was poor, despite the loadings for the other 23 items which were significant at $p<.01$. After removing item 17, improvement was found for CFI and TLI with values of .91 and .90 , respectively. The revised bifactor model provided a better model fit $\left(\right.$ WLSMV $\chi^{2}=1045.03, d f=207$, CFI $=.91$, TLI $=.90$, RMSEA $\left.=.05\right)$ than the original bifactor model (i.e., $\triangle \mathrm{CFI}=.01, \triangle \mathrm{TLI}=.02$ ). Although some factor loadings were low to moderate, all (except for item 17) were significant $(p<.01)$ (see Table 2). We therefore did not remove significant items from the following analyses. This decision was also supported by some of the other estimates. Specifically, the $\omega_{H}$ for the general factor was .77 , and the $\omega_{H S}$ was .31 for GM, .36 for $\mathrm{CU}, .37$ for DI, .14 for CD, respectively. Moreover, the computed explained common variance is .59 (see Table 2).

\section{Internal Consistency Indices of the PSCD}

In terms of internal consistency, the alpha for the 23-item PSCD (excluding the ODD item) total score was good $(\alpha=.80)$. This estimate indicates that the scale is reliable. It also indicated that the items are not highly redundant with regard to item content, which was a 
specific aim in the development of the measure. As expected, the coefficient alphas for the PSCD factor scores were lower due to the small number of items per subscale (e.g., .56 for GM, .51 for CU, .63 for DI, .69 for CD, respectively). In the present study, the MIC values were acceptable for factors of GM (.17), CU (.16), DI (.26), and CD (.27). In addition, and importantly, the McDonald's $\omega$ for the PSCD factor scores, which do not rely on number of items per scale, were acceptable (omega coefficients ranged from .69 to .81) and was good to excellent for the PSCD total score $(\omega=.90)$ (Cicchetti, 1994; Cicchetti \& Sparrow, 1990). Further, there were significant zero-order correlations among the factors of the PSCD, as well as the total score. Specifically, the inter-factor correlations ranged from .31 to $.42(p s<.001)$ and the correlations between PSCD factor and total scores were significant and strong ( $r \mathrm{~s}$ were from .67 to $.75, p s<.001)$ (see Table 3).

\section{Follow-up Model Analyses}

The bifactor model results support use of the total PSCD scale score, yet the pattern of significant group factor loadings suggests considerable meaningful variance that remains after the common variance of the general factor is accounted for. As such, we also re-tested a four-factor model, using only items with substantial item reliability for the GM (items 4, 5, 6), CU (7, 9, 10), DI $(13,14,15)$, and the four CD subtype items $(19,20,21,22)$. For the total sample, this 13-item model demonstrated excellent fit (WLSMV $\chi^{2}=286.32, d f=59$, $\mathrm{CFI}=.96, \mathrm{TLI}=.95, \mathrm{RMSEA}=.05)$. Figure 1 displays the standardized model parameters The standard errors for PSCD indicators for the GM (.02 - .03), CU (.04-.05), DI (.02-.03), and $\mathrm{CD}(.01-.03)$ factors were all quite small and provide further testament to the quality of the results. Similar small standard errors were evident for the factor correlations (.02-.03). Thus, as would be expected, all PSCD indicators and factor correlations were highly significant, $p \mathrm{~s}<.0001$. Also, using the same four factors model, we examined whether this 13 item-set demonstrated good fit within a strong invariance framework (equal loadings and 
thresholds) across the girls and boys, which it did (WLSMV $\chi^{2}=426.53, d f=136$, CFI $=.95$, $\mathrm{TLI}=.94, \mathrm{RMSEA}=.04)$. The strong invariance model showed no difference in fit from a configural model where the loadings and thresholds are allowed to be free across the girls and boys $\left(\mathrm{WLSMV} \chi^{2}=384.57, d f=118, \mathrm{CFI}=.95, \mathrm{TLI}=.93, \mathrm{RMSEA}=.04\right)$. These results provide further support for a four-factor model and the items demonstrated measurement invariance across sex, consistent with other cross-cultural research (Neumann, Schmitt, Carter, Embley, \& Hare, 2012). Standardized loadings and thresholds for girls and boys are presented in Figure 2.

Finally, it was possible to compare the 24 -item scale with the reduced 13 -item scale in terms of how well each scale identifies individuals with elevated features of psychopathy. Since the PSCD has a response scale similar to psychiatric ratings $(0,1,2)$ (e.g., Rogers, 2001), elevated features can be operationally defined in terms of mean item responses (e.g., 24-item PSCD scale total divided by 24). Mean item ratings greater than 1 suggest individuals who tended to endorse some PSCD items at threshold (i.e., 2). Given that the 13item model contains items with substantial information, we would expect this item-set to do well at identifying individuals with elevated PSCD features. The 24-item scale identified $5.2 \%$ of the sample with elevated features, while the 13 -item scale identified $5.8 \%$, and the difference in proportions was significant $\left(\chi^{2}(1)=378.93, p<.001\right)$ in favor of the 13 -item model; however, it should be noted that the fit statistics differ minimally (and likely nonmeaningfully on a clinical level, and the 13-item scale highly correlates with the 24-item scale $(r=.92 ; p<.0001)$.

\section{Convergent and Discriminant Validity of the PSCD}

To examine the convergent and discriminant validity of the PSCD, we first tested the relation between the PSCD and other psychopathy measures (i.e., APSD, YPI) and a component scale (i.e., ICU). Second, we tested the relation between psychopathy and two 
forms of psychopathology thought to be less related to psychopathy, namely, Generalized Anxiety Disorder (GAD) and Clinical Depression (Dep). A major concern for measures of psychopathology, including psychopathy, is that they may not have sufficient convergent validity with similar measures as well as potentially insufficient discriminant validity. Both forms of validity are important in order to show that the scale is tapping its intended construct but also effectively discriminating from other forms of less related mental disorders. In youth samples, negative affect is occasionally positively related to psychopathic traits (Kubak \& Salekin, 2009; Ray et al., 2016), but we, nonetheless, expected the PSCD to show greater convergence with the other measures of externalizing psychopathology and lower levels of convergence with internalizing pathology. Thus, we used the GAD and Dep variables because they are expected to diverge with psychopathy but also offer a stringent test of discriminant validity. We, therefore, expected GAD and Dep to be less related to psychopathy (e.g., GAD, Spitzer et al., 2006; PHQ-Dep, Kroenke et al., 2001; Salekin, Neumann, Leistico, \& Zalot, 2004).

As can be seen in Table 3 the correlations between the PSCD and alternate measures of psychopathy are generally high (.647 with the APSD, .595 with the YPI, and .335 with the ICU) and these correlations exceed the correlations between the PSCD total score and i) GAD (.168) and ii) Dep (.213). No violations were evidenced with either GAD or Dep, where their correlations exceeded the correlations of psychopathy with psychopathy scales. This information tells us that the PSCD has discriminant validity with GAD and Depression. We further examined convergent validity by determining whether the validity coefficients were significantly different from zero and substantial in magnitude (Byrne \& Goffin, 1993). Fiske and Campbell (1992) have indicated that successful validity coefficients are typically at the .30 to .50 range. The convergent validity estimates exceed these recommended estimates. 
Moreover, the PSCD subscale scores were generally weakly correlated with the symptoms of GAD and Depression (see Table 3). Specially, the GM and DI scales were non-significantly related to GAD score ( $r$ 's $=.035, .068, p s>.05$, respectively), though the CU and CD scales showed relatively modest positive correlations, $(r$ 's $=.156, .220, p s<.001)$. Additionally, the GM scale was uncorrelated with PHQ depression $(r=.033)$, but the CU, DI, and CD showed small positive correlations with depression $(r ' s=.187, .123, .269, p s<.01-.001$, respectively). CD exhibited the highest relation with depression (see Table 3).

\section{Convergent and Discriminant Validity of the Psychopathy Sub-factors}

A multitrait-multimethod matrix was produced to examine the convergent and discriminant validity of the different variables associated with psychopathy. The multitraitmultimethod matrix allows for the comparison of the relative strength of the validity coefficients (monotrait-heteromethod) to other correlation coefficients for the same measure (heterotrait-heteromethod) and across measures. Again, we examined convergent validity by determining whether the validity coefficients were significantly different from zero and substantial in magnitude, typically at, or exceeding, the .30 to .50 range (Byrne \& Goffin, 1993; Fiske \& Campbell, 1992; Hemphill, 2003).

According to these standards, there is strong evidence of convergent validity for the PSCD (.647 APSD, .595 YPI; .335 ICU). Convergent validities were higher than both monotrait-heteromethod and heterotrait-heteromethod correlation coefficients showing good discriminant validity. Using the a priori standards for interpretation (Bagozzi \& Yi, 1991; Byrne \& Goffin, 1993), we estimated the degree of discriminant validity based on the following estimates: (a) high degree of discriminant validity (<5\% comparison violations); (b) moderate discriminant validity 6-33\% violations); and (c) low discriminant validity (> $33 \%$ violations). As can be seen from the matrix, the PSCD and YPI subscales demonstrated moderate convergent discriminant validity (16.6\%) comparison violations whereas the APSD 
showed a higher number of violations (33\%) (see Table 4). However, this is a difficult test of convergent discriminant validity and all three tests performed well given the stringency.

\section{The PSCD and External Criteria}

We examined the PSCD's relation to the external criteria indices of conduct problems (e.g., Rule-Breaking behavior, Aggressive behavior, Reactive Aggression, and Proactive Aggression, via two measures, namely the YSR and RPQ) (see Table 3). The PSCD total score and its subscales were significantly and positively related to children's aggressive behavior. More specifically, the correlations between PSCD total scale were significantly correlated with the YSR total scores and its subscales $(r$ 's $=.640, .523$, and $.607, p s<.001$, respectively). As expected, the correlations between PSCD scale scores were significantly correlated with subscales of the YSR, ranging from .288 to $.610, p s<.001$. Further, the PSCD total score was strongly related to the RPQ total scale and its subscales ( $r$ 's $s=.554$, .461 , and $.462, p s<.001$, respectively). Similarly, the PSCD scale scores significantly correlated with subscales of the RPQ, ranging from .229 to $.401, p s<.001$.

\section{Discussion}

The aim of the current study was to examine the factor structure and construct validity of the self-report PSCD in a relatively large sample of Chinese community adolescents. Confirmatory factor analyses supported the bifactor model consisting of four factors (GM, CU, DI, and CD) and a general psychopathy factor. Follow-up model analyses with a reduced PSCD item set also strongly supported a four-factor model. Furthermore, the internal consistency for the PSCD total and factor scores was reasonable especially given the brief number of items per scales. The correlations between PSCD scores and other psychopathy measures and external criterion variables supported the convergent, discriminant, and criteria related validity of the PSCD scores. Overall, our findings provide preliminary support for the 
utility of the self-report PSCD for assessing psychopathic traits in youths within China. We provide further discussion of the primary findings for the current study.

\section{Factor Structure of the PSCD}

Although the three- and four-factor models of psychopathy have been extensively examined (cf., Hare \& Neumann, 2005; 2008), researchers still need to make new efforts for accurately depicting the broader construct and its components (Salekin, 2016ab, 2017). The PSCD addresses four dimensions (i.e., GM, CU, DI, and CD) that are intended to allow for the assessment of the three dimensions of psychopathy plus CD (Salekin, Andershed, \& Clark, 2018). Moreover, the CD scale allows for the assessment of the four key CD symptom categories of $\mathrm{CD}$, as well as one category of Oppositional Defiant Disorder that are delineated in the DSM-5. For this reason, it is hoped that the PSCD may ultimately aid in future descriptive, etiologic, and treatment investigations where CD and psychopathic personality dimensions are of interest (Salekin \& Hare, 2016; see also Andershed et al., 2018; Colins et al., 2018; Fanti et al., 2018; Somma et al., 2018).

No published studies have tested the PSCD with adolescents and the current investigation fills a necessary gap in research pertaining to the factor structure of the PSCD by comparing and evaluating the model fit for the one-factor model, the original four-factor solution, the second-order model, and the bifactor model. For the full 24-item set, the CFAs showed that the four-factor bifactor model was superior to other models (i.e., the one-factor model, the four-factor structure (Salekin \& Hare, 2016), and the second-order solution). We were interested in determining if a smaller set of items could also be modeled and represent the PSCD. Modeling results with the reduced 13-item set provided support for a four-factor model in-line with other studies (Hare, 2003; Neumann et al., 2015; Salekin et al., 2006). The findings suggest that psychopathy is a multifaceted construct that can be modeled with CD. The vast majority of items performed reasonably well in the bifactor analyses. However, one 
item (item 17), I like to live in the moment, did not load significantly on the general factor and model fit (CFI and TLI) improved when without this item. The minor revised bifactor solution provided better fit than the original model. This may be an indication that the test item of living in the moment may need rewording or may not be applicable in China.

Consistent with other psychopathy measures such as the self-report YPI scores (e.g., Wang et al., 2017; Zwaanswijk et al., 2017), our findings provide evidence for multidimensional models of the self-report PSCD. The findings suggest that conceptualizations of psychopathy should not primarily focus on a single element of the psychopathy construct, such as CU traits, and risk losing sight as to how other elements of psychopathy might relate to critical external correlates, and thus potentially end up with a narrow, and one component view, of child psychopathy. This notion is in line with recent arguments on the importance of examining the multidimensional aspects of psychopathy as well as total scores in relation with conduct problems (Andershed et al., 2018; Colins et al., 2018; Fanti et al., 2018; Lee et al., 2018; Lilienfeld, 2018; Salekin, 2017; Salekin et al., 2018; Somma et al., 2018).

Likewise, regarding the clinical use of the PSCD, the adequate fit of the bifactor model speaks to critical role of using total scores to determine an individual's overall level of psychopathy, but also, our follow-up modeling results speak to the importance of examining the subcomponents of psychopathy. By doing so, clinicians and researchers will be able to produce detailed profiles of youth on key dimensions of psychopathy. We believe that the PSCD and its general structure, reflect how many psychologists or clinicians would spontaneously make use of the psychopathy, and PSCD information, similar to what has been pursued to some extent with adult psychopathic samples (e.g., Hare, 2003; Krstic et al., 2018).

\section{Internal Consistency of the PSCD}


The internal consistency for the PSCD was high at the total score level. While the alpha coefficients of the PSCD factor scores were lower, mean inter-item correlations (MICs) also showed that the PSCD total and factor scores had acceptable internal consistencies indices (alpha comparisons cannot be made between total and factor scores due to the differing number of items; Clark \& Watson, 1995). Model-based McDonald's $\omega$ which was also used as an alternative estimate of reliability suggested good-to-excellent reliability for the PSCD total scores and moderate reliability for the factor scores (Cicchetti \& Sparrow, 1990). This shows that importantly, the PSCD has some diversity with regard to its reflection of psychopathy. Very high alphas are oftentimes obtained when questionnaires repeatedly ask the same question with somewhat different wording, thereby missing out on the various traits that reflect the disorder. Our findings indicate that the PSCD scores had sufficient internal consistency while at the same time representing psychopathic traits more broadly and from theory, showing the condition to have differing elements (Cleckley, 1976; Hare, 2003).

\section{Convergent, Discriminant, and Criteria Validity of the PSCD}

To examine the convergent validity for the PSCD, we generated the correlations between the PSCD scores with three other psychopathy measures. As expected, The PSCD total score was significantly related to alternate psychopathy scales demonstrating good convergent validity. Furthermore, to test the discriminant validity for the PSCD, the correlations between the PSCD scores with two mental disorders (e.g., Anxiety, and Depression; Kroenke et al., 2001; Spitzer et al., 2006) was shown to have satisfactory discriminant validity through its correlation with other mental disorders that were different from psychopathic traits (Salekin et al., 2004). Interestingly, at the scale level, GM traits showed the lowest correlations with Anxiety and Depression, thereby exhibiting the best discrimination from other forms of pathology. The average correlations across Depression and Anxiety were $.034, .172, .096$, and .245, for GM, CU, DI, and CD, respectively. While 
not large associations in this non-clinical sample, these findings are consistent with other research at the childhood level and suggest that irritability may play a role in the expression of psychopathic features, although here it seems to be most related to CD (e.g., Garofalo, Neumann, \& Velotti, 2018).

\section{Convergent and Discriminant Validity of Factors}

Findings from the current study demonstrated that the factor scores for the PSCD were significantly and positively related to the corresponding factor scores on the APSD and YPIS. The only scale violations noted was for the CU scales of the APSD, PSCD, and YPI. Specifically, although the PSCD and YPI showed convergent and discriminant validity, with no comparison violations, the APSD did show some violations especially with the CU traits scale. This may signify that the APSD CU scale is measuring something different than the PSCD and YPI CU scales. Despite this one noted discrepancy, the results of the correlations generally indicated significant convergence of these subscales and sufficient divergence from alternate subscales on the psychopathy measure. These findings provide further evidence that the PSCD may potentially serve as a valid and reasonable alternative for child psychopathic traits measures.

\section{Criterion Related Validity}

The criteria validity of the PSCD scores was validated through Pearson product-moment correlations between PSCD scores and external measurements (e.g., aggressive behavior). Consistent with prior psychopathy studies (e.g., Colins et al., 2017; Goodwin et al., 2015; Wang et al., 2015), the psychopathic traits showed the expected relations with children's aggressive behavior. Specifically, the PSCD total and scale scores were significantly and moderately to strongly related with the YSR and its subscales (Fiske \& Campbell, 1992; Hemphill, 2003). Also, the PSCD total and scale scores were significantly related to the RPQ and its subscales. The results supported the criterion validity of the PSCD (Colins et al., 
2017; Forth \& Book, 2010; Frick et al., 2014). In sum, psychopathy was significantly related to aggressive behavior including both reactive and proactive aggression, future studies should examine the underlying mechanism between psychopathy, especially the PSCD scores and external variable measures (e.g., externalizing and internalizing conduct problems).

\section{Psychopathy and Prevalence}

Interestingly, the current study showed that the prevalence for psychopathic traits in this Chinese sample was around 5\%. This study therefore offers new information on potential prevalence rates for these symptoms in child samples. Little is known about this topic. Based on other large sample research with young adult community participants (Colins, Fanti, Salekin, \& Andershed, 2017), a prevalence rate for males and females with elevated psychopathic traits was $12 \%$ for both sexes. Also, based on general models of personality low levels of conscientiousness and agreeableness can be quite prevalent. Other studies show the prevalence rate of psychopathy to be $1-2 \%$ in the general population (Hare, 1993). If this is the case, then more research may needed to learn what takes a portion of youth off the track for adult psychopathic personality. While the prevalence rates for psychopathy are still so unclear, and we cannot establish a clear prevalence rate at this point, with this age band, the current study does provide some new information on prevalence. If it is determined that prevalence does drop in adulthood, then an interesting question that arises is what seems to account for this drop in psychopathic traits across development.

\section{Research and Clinical Implications for the PSCD: Full Version of the PSCD versus the}

\section{3-item PSCD}

Questions may arise as to how the PSCD might be used Research and Clinical settings. Moreover, questions may arise as to what version of the PSCD might be best for use in research settings and potentially clinical settings. At this point, it is too early to confirm that either the 13-item or 24-item version has superior psychometric properties for research or 
clinical practice. Rather, both scales exhibit promising psychometric properties. We see the 13-item version as a brief version of the PSCD that might eventually be used in studies where test batteries are already fairly lengthy with limited space remaining. These might be studies where psychopathy is of interest, but perhaps not the primary study variable. The 24 -item version may be best utilized in studies where psychopathy is the chief study variable of interest and the researchers want to examine a broader set of psychopathic traits in relation to $\mathrm{CD}$ and ODD. There remains a considerable amount of information to learn regarding the specific items that underlie each dimension as well as how the dimensions interact with one another (Salekin, 2016b). In addition, there is additional research needed to test the brief CD scale of the PSCD with clinical diagnoses of CD. The 13-item set may also reflect the cultural differences as the items seem to offer the most signal in this specific Chinese sample. Additional studies will be needed to determine if the results generalize and if the findings replicate, additional research will be needed to determine why. If the 13 items are specific to Chinese samples then additional research might be needed to further tailor items. The 24-item PSCD should allow for the best and most comprehensive investigation of these topics. And, there could be some risk with the 13-item version if the model is specific to the current sample and does not replicate further across varied samples.

Eventually, the clinical use of the PSCD may be considered. The PSCD could bolster what we know about young individuals with conduct problems by assessing key personality traits in young individuals in conjunction with CD. The PSCD scale could facilitate this process, but would need additional validation and would have to be used in conjunction with other assessment instruments. For instance, after further validation, the PSCD could be used with structured interviews that index CD (e.g., KSADS; DICA, DISC). In this manner, the PSCD could provide critical information for clinicians regarding the specific set(s) of personality traits that accompany CD, both as it is indexed on the PSCD but also through 
interview. This would enable the assessment of traits that Quay (1987) believed were so important to facilitating clinicians' understanding of $\mathrm{CD}$. The use of structured clinical interviews such as the KSADS, DICA, or DISC would also allow for a broader assessment of psychopathology and thus a comprehensive assessment of other potential psychological problems. This would be critical for better understanding the complex set of problems young individuals have as well as allow for differential diagnoses. The PSCD, similar to other personality instruments, would need to be utilized in conjunction with other collateral source information. Collateral source information could include relevant school records, disciplinary records, work records, and police records (arrests). The 24- item version will be more comprehensive and thus would be best for clinical purposes although more research is needed on the scale and research may indicate revisions. Time durations for how long the symptoms should be present will require consideration. While further work is needed, personality based information to inform $\mathrm{CD}$ will ultimately facilitate our understanding of the etiology and treatment of CD (Salekin, 2016b).

The potential drawbacks of considering personality traits, and specifically the use of the PSCD self-report measure, is that it is reliant on the one source of information - the young individual and the personality traits are oftentimes viewed as more permanent than behavior. Because if this we would argue that peer, parent, and teacher sources of information, either through PSCD assessment or other, should also be considered and potentially utilized along with the interview based methods mentioned above to provide the most reliable information. Another potential risk of any personality based method, is the permanency of the traits and the potential stigmatizing effect of the use of personality traits. However, we would argue that there is now substantial research to show that youth can come off a trajectory of psychopathic traits showing that there is some malleability to the traits (Andershed, 2010). Similarly some treatment programs have shown preliminary positive effects for psychopathic 
traits. We believe that a failure to recognize the science illuminating the multidimensionality, and early observability, and the distinct correlates, of psychopathic traits in conjunction with $\mathrm{CD}$ could also prove to be harmful in the long-run as effective treatments will remain elusive. On the other hand, the inclusion of the PSCD and other personality based measures will result in greater clinical resolution for specifying and understanding CD, which in turn, should result in better treatment protocols specific to the varying profiles of youth with $\mathrm{CD}$ and psychopathic traits.

\section{The PSCD Compared with Other Childhood Psychopathy Measures}

Some questions may also arise regarding the difference between the PSCD and other child psychopathy scales (e.g., the APSD, CPTI, YPI). It should be noted that there are a number scholars who have moved the field forward on this topic with alternate measures and likely will continue to promote new knowledge (Andershed et al., 2018; Colins et al., 2018; Frick et al., 2012). This has reflected important work and some have recently argued for the more comprehensive assessment of psychopathy to better understand conduct problems and CD (Andershed et al., 2018; Colins et al., 2018; Fanti et al., 2018; Salekin, 2017; Salekin et al., 2018; Somma et al., 2018; Lee, 2018; Lilienfeld, 2018). One primary design difference that separates the PSCD from other child psychopathy measures is that the PSCD is developed to measure psychopathic traits along with $\mathrm{CD}$. This is not an option with any other child psychopathy measure. The inclusion of $\mathrm{CD}$ items allows for the direct examination of psychopathic traits in conjunction with $C D$ within the same measure. Moreover, the PSCD allows for the assessment of the four subtypes of $\mathrm{CD}$, albeit with only one item per category. And, the PSCD has one ODD item that can help with the study of ODD and its relation to psychopathic traits in youth. Finally, the PSCD scales (GM, CU, and DI) are designed to offer greater theoretical coherency. Specifically, in many psychopathy models some traits cohere (the GM and CU traits) while others potentially reduce homogeneity (impulsivity). 
The PSCD DI scale is configured to emphasize daring and risk-taking traits as opposed to impulsivity items. This aspect of the PSCD is intended to reduce contrasting items (manipulation vs. inability to plan; absence of nervousness vs. impulsivity) and reduce overlap between PSCD items and ADHD symptoms.

Although other measures may be utilized, the PSCD can be used to examine CD profiles and configurations of symptoms via latent profile analyses (LPA) as well as also examine the best functioning items through IRT studies. This will allow for the testing of the novel proposed specifiers for $\mathrm{CD}$ with respect to profile analyses, and information gleaned from such examination may help determine whether a broader set of CD specifiers should eventually be considered for revisions to the DSM-6 and ICD-12. This will also help with the specific items that should be utilized. While the PSCD was designed to bolster what is known about CD subtyping schemes and youth psychopathy by providing a measure that could be relatively easily incorporated into test batteries, it is also expected that revisions will be needed as additional research emerges.

\section{Limitations and Future Direction}

The findings of this study should be considered in light of its limitations. First, participants in the current study were predominantly recruited from mainland (southern) China, so the results may not generalize to other geographic areas or cultures. Additional studies should further examine and replicate our findings in other regions in China or Western samples. Second, data for this investigation were collected only through self-report instruments, and some of these self-reports were abbreviated versions used to reduce fatigue, but at the same time may have also reduced reliability estimates. As such, future work is warranted to test the PSCD scores with fuller length scales and reports by third-party informants (e.g., parents and / or teachers report). There have been some studies that have examined parent and child report together and have shown greater magnitude of effect for 
parent measures in predicting some outcomes (Falkenbach et al., 2003; White et al., 2009) and in some studies the scales differentially predict negative outcome (e.g., White et al., 2009). Therefore, future research is needed for both self and parent (other) report (Falkenbach et al., 2003; Muñoz \& Frick, 2007; White et al., 2009). Third, external criteria of the PSCD is limited at present study, therefore, other criteria relevant to the psychopathy concepts should be considered, such as cognitive functioning (e.g., Salekin et al., 2004), emotional intelligence (Megías, Gómezleal, Gutiérrezcobo, Cabello, \& Fernández-Berrocal, 2018), and prosocial behavior (Vahl, Colins, Markus, Lodewijkcs, Doreleijers, \& Vermeiren, 2014). Fourth, we did not have temporal stability data on psychopathic traits for this group, although there is considerable data to show modest-to-high stability for child psychopathic traits (see Andershed, 2010; Muñoz \& Frick, 2007). Finally, we only examined the psychometric properties of the PSCD with community adolescents, further work should be considered to evaluate the PSCD in clinic-referred or justice-involved samples where the concentration of psychopathic traits is likely to be even higher. Despite these limitations, the current study also has considerable strengths as it is the first study to examine the psychometric properties of the PSCD scores with community youth in China. Overall, the findings of the current study suggest that the self-report version of the PSCD holds promise as a youth-report instrument for assessing psychopathy in Chinese community adolescents. Ultimately, the PSCD, along other similar psychopathy measures, might better help us understand the personality traits that accompany $\mathrm{CD}$, and thus, improve what we know about the etiology and treatment of young individuals with CD in community, clinical, and justice involved settings. 


\section{References}

Achenbach, T. M. (1991). Manual for the YSR and 1991 profile. Burlington, VT: University of Vermont, Department of Psychiatry.

Andershed, H. (2010). Stability and change of psychopathic-traits. What do we know? In R. T. Salekin \& D. R. Lynam (Eds.), Handbook of child and adolescent psychopathy (pp. 233-250). New York, NY: Guilford Press.

Andershed, H., Colins, O. F., Salekin, R. T., Lordos, A., Kyranides, M., N., \& Fanti, K. A. (2018). Callous-unemotional traits only versus the multidimensional psychopathy construct as predictors of various antisocial outcomes during early adolescence. Journal of Psychopathology and Behavioral Assessment, 40, 1625.https://doi.org/10.1007/s10862-018-9659-5

Andershed, H., Kerr, M., Stattin, H., \& Levander, S. (2002). Psychopathic traits in nonreferred youths: Initial test of a new assessment tool. In E. Blaauw, J. M. Philippa, K. C. M. P. Ferenshild, \& B. Van Lodesteijn (Eds.), Psychopaths: Current international perspectives (pp. 131-158). The Hague: Elsevier.

Bagozzi, R. P., Yi, Y. (1991). Multitrait-multimethod matrices in consumer research. Journal of Consumer Research, 17, 426-439. http://dx.doi.org/10.1086/208568.

Bijttebier, P., \& Decoene, S. (2009). Assessment of psychopathic traits in children and adolescents: Further validation of the Antisocial Process Screening Device and the childhood psychopathy scale. European Journal of Psychological Assessment, 25, 157163. http://dx.doi.org/10.1027/1015-5759.25.3.157.

Bonifay, W., Lane, S. P., \& Reise, S. P. (2017). Three concerns with applying a bifactor model as a structure of psychopathology. Clinical Psychological Science, 5, 184-186. http://dx.doi.org/10.1177/2167702616657069. 
Burke, J. D., Loeber, R., \& Lahey, B. B. (2007). Adolescent conduct disorder and interpersonal callousness as predictors of psychopathy in young adults. Journal of Clinical Child \& Adolescent Psychology, 36, 334-346.

Byrne, B. M., \& Goffin, R. D. (1993). Modeling MTMM data from additive and multiplicative covariance structures: An audit of construct validity concordance. Multivariate Behavioral Research, 28, 67-96.

Caputo, A. A., Frick, P. J., \& Brodsky, S. L. (1999). Family violence and juvenile sex offending: The potential mediating role of psychopathic traits and negative attitudes toward women. Criminal Justice and Behavior, 26, 338-356.

Cicchetti, D. V. (1994). Guidelines, criteria, and rules of thumb for evaluating normed and standardized assessment instruments in psychology. Psychological Assessment, 6, 284290.

Cicchetti, D. V., \& Sparrow, S. S. (1990). Assessment of adaptive behavior in young children. In J. J. Johnson and J. Goldman (Eds.), Handbook of mental retardation (pp. 173-196). New York, NY: Pergamon Press.

Clark, L. A., \& Watson, D. (1995). Constructing validity: Basic issues in objective scale development. Psychological Assessment, 7, 309-319.

Colins, O. F., Andershed, H., Frogner, L., Lopez-Romero, L., Veen, V., \& Andershed, A. K. (2014). A new measure to assess psychopathic personality in children: The Child Problematic Traits Inventory. Journal of Psychopathology and Behavioral Assessment, 36, 4-21. http://dx.doi.org/10.1007/s10862-013-9385-y.

Colins, O. F., Andershed, H., Salekin, R. T., \& Fanti, K. A. (2018). Comparing different approaches for subtyping children with conduct problems: Callous-unemotional traits only versus the multidimensional psychopathy construct. Journal of Psychopathology and Behavioral Assessment, 40, 6-15. https://doi.org/10.1007/s10862-018-9653-y 
Colins, O. F., Fanti, K., Larsson, H., \& Andershed, H. (2017). Psychopathic traits in early childhood further validation of the child problematic traits inventory. Assessment, 24, 602-614. http://dx.doi.org/10.1177/1073191115624544.

Colins, O. F., Fanti, K. A., Salekin, R. T., \& Andershed, H. (2017). Psychopathic personality in the general population: Differences and similarities across gender. Journal of Personality Disorders, 31, 49-74. http://dx.doi.org/10.1521/pedi_2016_30_237.

Cooke, D. J., \& Michie, C. (2001). Refining the construct of psychopathy: Towards a hierarchical model. Psychological Assessment, 13, 171-188. http://dx.doi.org/10.1037/1040-3590.13.2.171.

Dillard, C. L., Salekin, R. T., Barker, E. D., \& Grimes, R. D. (2013). Psychopathy in adolescent offenders: An item response theory study of the antisocial process screening device-self report and the Psychopathy Checklist: Youth Version. Personality Disorders: Theory, Research, and Treatment, 4, 101-120. http://dx.doi.org/10.1037/a0028439.

Embretson, S. E., \& Hershberger, S. L. (1999). The new rules of measurement: What every psychologist and educator should know. Psychology Press.

Falkenbach, D. M., Poythress, N. G., Heide, K. M. (2003). Psychopathic features in a juvenile diversion population: Reliability and predictive validity of two-self-report measures. Behavioral Sciences and the Law, 21(6), 787-805. https://doi.org/10.1002/bsl.562

Farrington, D. P. (2005). The importance of child and adolescent psychopathy. Journal of Abnormal Child Psychology, 33, 489-497.

Fiske, D. W., \& Campbell, D. T. (1992). Citations do not solve problems. Psychological Bulletin, 112, 393-395. http://dx.doi.org/10.1037/0033-2909.112.3.393. 
Flora, D. B., \& Curran, P. J. (2004). An empirical evaluation of alternative methods of estimation for confirmatory factor analysis with ordinal data. Psychological Methods, 9, 466-491. http://dx.doi.org/10.1037/1082-989X.9.4.466.

Forth, A. E., \& Book, A. S. (2010). Psychopathic traits in children and adolescents: The relationship with antisocial behaviors and aggression. In R. T. Salekin \& D. T. Lynam (Eds.), Handbook of Child and Adolescent Psychopathy (pp. 251-283). New York, NY: The Guilford Press.

Forth, A. E., Hart, S. D., \& Hare, R. D. (1990). Assessment of psychopathy in male young offenders. Psychological Assessment, 2, 342-344. http://dx.doi.org/10.1037/10403590.2.3.342.

Forth, A. E., Kosson, D. S., \& Hare, R. D. (2003). The Hare Psychopathy Checklist: Youth Version. Toronto, ON, Canada: MultiHealth Systems.

Frick, P. J. (2004). Inventory of Callous-Unemotional Traits. Unpublished rating scale, University of New Orleans.

Frick, P. J., Barry, C. T., \& Kamphaus, R. (2005). Clinical assessment of child and adolescent personality and behavior ( $3^{\text {rd }}$ ed). Springer.

Frick, P. J., Bodin, S. D., \& Barry, C. T. (2000). Psychopathic traits and conduct problems in community and clinic-referred samples of children: Further development of the psychopathy screening device. Psychological Assessment, 12, 382-393.

Frick, P. J., \& Hare, R. D. (2001). The Antisocial Process Screening Device. Toronto: MultiHealth Systems.

Frick, P. J., Kimonis, E. R., Dandreaux, D. M., \& Farell, J. M. (2003). The 4 year stability of psychopathic traits in non-referred youth. Behavioral Science and Law, 21, 713-736.

Frick, P. J., O’Brien, B. S., Wootton, J. M., \& McBurnett, K. (1994). Psychopathy and conduct problems in children. Journal of Abnormal Psychology, 103, 700-707. 
Frick, P. J., Ray, J., Thornton, L., \& Kahn, R. E. (2014). Can callous-unemotional traits enhance the understanding, diagnosis, and treatment of serious conduct problems in children and adolescents? A comprehensive review. Psychological Bulletin, 140, 1-57. http://dx.doi.org/10.1037/a0033076.

Fung, A. L. C., Raine, A., \& Gao, Y. (2009). Cross-cultural generalizability of the ReactiveProactive Aggression Questionnaire (RPQ). Journal of Personality Assessment, 91, 473479. http://dx.doi.org/10.1080/00223890903088420.

Gao, Y., Zhang, W., Fung, A. L. C. (2015). The associations between parenting styles and proactive and reactive aggression in Hong Kong children and adolescents. International Journal of Psychology, 50, 463-471. http://dx.doi.org/10.1002/ijop.12104.

Garofalo, C., Neumann, C. S., \& Velotti, P. (2018). Difficulties in emotion regulation and psychopathic traits in violent offenders. Journal of Criminal Justice, 57, 116-125. http://dx.doi.org/10.1016/j.jcrimjus.2018.05.013.

Gillen, C. T. A., MacDougall, E. A. M., Forth, A. E., Barry, C. T., \& Salekin, R. T. (2019). Validity of the Youth Psychopathic Traits Inventory-Short Version in justice-involved and at-risk adolescents. Assessment, 26,479-491. http://dx.doi.org/10.1177/1073191117700723.

Goodwin, B. E., Sellbom, M., \& Salekin, R. T. (2015). Elucidating the construct validity of the Antisocial Process Screening Device (APSD) in a sample of young adults. Journal of Psychopathology and Behavioral Assessment, 37, 1-11. http://dx.doi.org/10.1007/s10862-014-9444-z.

Hare, R. D. (2003). Manual for the revised psychopathy checklist (2nd rev. Eds.). Toronto, Ontario, Canada: Multi-Health Systems.

Hare, R. D., \& Neumann, C. S. (2005). Structural models of psychopathy. Current Psychiatry Reports, 7, 57-64. http://dx.doi.org/10.1007/s11920-005-0026-3. 
Hare, R. D., \& Neumann, C. S. (2008). Psychopathy as a clinical and empirical construct. Annual Review of Clinical Psychology, 4, 217-246. http://dx.doi.org/10.1146/annurev.clinpsy.3.022806.091452.

Hare, R. D., Neumann, C. S., \& Mokros, A. (2018). The PCL-R assessment of psychopathy: Development, properties, debates, and new directions. In C. J. Patrick (Ed.), Handbook of psychopathy (pp. 39-79). New York, NY, US: The Guilford Press.

Harpur, T. J., Hare, R. D., \& Hakstian, A. R. (1989). Two-factor conceptualization of psychopathy: Construct validity and assessment implications. Psychological Assessment: A Journal of Consulting and Clinical Psychology, 1, 6-17. http://dx.doi.org/10.1037/1040-3590.1.1.6.

Hemphill, J. F. (2003). Interpreting the magnitudes of correlation coefficients. American Psychologist, 58, 78-79. http://dx.doi.org/10.1037/0003-066X.58.1.78.

Hoppenbrouwers, S. S., Neumann, C. S., Lewis, J., \& Johansson, P. (2015). A latent variable analysis of the Psychopathy Checklist-Revised and behavioral inhibition system/behavioral activation system factors in North American and Swedish offenders. Personality Disorders: Theory, Research, and Treatment, 6, 251-260. http://dx.doi.org/10.1037/per0000115.

Hopwood, C. J., \& Donnellan, M. B. (2010). How should the internal structure of personality inventories be evaluated? Personality and Social Psychology Review, 14, 332-346. http://dx.doi.org/10.1177/1088868310361240.

Hu, L., \& Bentler, P. M. (1999). Cutoff criteria for fit indexes in covariance structure analysis: Conventional criteria versus new alternatives. Structural Equation Modeling, 6, 1-55. http://dx.doi.org/10.1080/10705519909540118.

IBM Corp. (2013). IBM SPSS Statistics for Windows, Version 22.0. Armonk, NY: Author. 
Kosson, D. S., Neumann, C. S., Forth, A. E., Salekin, R. T., Hare, R. D., Krischer, M. K., \& Sevecke, K. (2013). Factor structure of the Hare Psychopathy Checklist: Youth Version (PCL: YV) in adolescent females. Psychological Assessment, 25, 71-83. http://dx.doi.org/10.1037/a0028986.

Kotler, J. S., \& McMahon, R. J. (2005). Child psychopathy: Theories, measurement, and relations with the development and persistence of conduct problems. Clinical Child and Family Psychology Review, 8, 291-325. http://dx.doi.org/10.1007/s10567-005-8810-5.

Kotler, J. S., \& McMahon, R. J. (2010). Assessment of child and adolescent psychopathy. In R. T. Salekin and D. R. Lynam (Eds.), Handbook of child and adolescent psychopathy (pp. 79-109). New York, NY: Guilford Press.

Kroenke, K., Spitzer, R. L., \& Williams, J. B. W. (2001). The PHQ-9: Validity of a brief depression severity measure. Journal of General Internal Medicine,16, 606-613. http://dx.doi.org/10.1046/j.1525-1497.2001.016009606.x.

Krstic, S., Neumann, C. S., Roy, S., Robertson, C. A., Knight, R. A., \& Hare, R. D. (2018). Using latent variable- and person-centered approaches to examine the role of psychopathic traits in sex offenders. Personality Disorders: Theory, Research, and Treatment, 9, 207-216. http://dx.doi.org/10.1037/per0000249.

Kubak, F. A., \& Salekin, R. T. (2009). Psychopathy and anxiety in children and adolescents: New insights on developmental pathways to offending. Journal of Psychopathology and Behavioral Assessment, 31, 271-284. http://dx.doi.org/10.1007/s10862-009-9144-2.

Latzman, R. D., Lilienfeld, S. O., Latzman, N. E., \& Clark, L. A. (2013). Exploring callous and unemotional traits in youth via general personality traits: An eye toward DSM-5. Personality Disorders: Theory, Research, and Treatment, 4, 191-202. http://dx.doi.org/10.1037/a0000001. 
Leung, P. W., Kwong, S. L., Tang, C. P., Ho, T. P., Hung, S. F., Lee, C. C., ... \& Liu, W. S. (2006). Test-retest reliability and criterion validity of the Chinese version of CBCL, TRF, and YSR. Journal of Child Psychology and Psychiatry, 47, 970-973.

Liu, T., You, X., Mai, Y., Gao, Y., \& Wang, M.-C. (2019). Developing a simplified version of the Reactive-Proactive Aggressive Questionnaire based on factor analysis and item response theory. Manuscript under review.

Loney, B. R., Frick., P. J., Clements, C. B., Ellis, M. L., \& Kerlin, K. (2003). Callousunemotional traits, impulsivity, and emotional processing in antisocial adolescents. Journal of Clinical Child and Adolescent Psychology, 32, 66-80.

López-Romero, L., Molinuevo, B., Bonillo, A., Andershed, H., Colins, O. F., Torrubia, R., \& Romero, E. (2018). Psychometric properties of the Spanish version of the Child Problematic Traits Inventory in 3- to 12-year-old Spanish children. European Journal of Psychological Assessment. Advance online publication. http://dx.doi.org/10.1027/1015$5759 / \mathrm{a} 000458$.

López-Romero, L., Romero, E., Colins, O. F., Andershed, H., Hare, R. D., \& Salekin, R. T. (2019). Proposed Specifiers for Conduct Disorder (PSCD): Preliminary validation of the parent version in a Spanish sample of preschoolers. Psychological Assessment, 31, 13571367. http://dx.doi.org/10.1037/pas0000759.

Luo, J., Wang, X., Wang, M.-C., Zhang, X., Deng, J., Zhong, C., ... Qi, S. (2019). Longitudinal measurement invariance of the Child Problematic Traits Inventory in older Chinese children. PLoS ONE, 14, e0219136. http://dx.doi.org/10.1371/journal.pone.0219136.

Lynam, D. R., Caspi, A., Moffitt, T. E., Loeber, R., \& Stouthamer-Loeber, M. (2007). Longitudinal evidence that psychopathy scores in early adolescence predict adult psychopathy. Journal of Abnormal Psychology, 116, 155-165. 
Lynam, D. R., \& Gudonis, L. (2005). The development of psychopathy. Annual Review of Clinical Psychology, 1, 381-407. http://dx.doi.org/10.1146/annurev.clinpsy.1.102803.144019.

Lynam, D. R., \& Miller, J. D. (2012). Fearless dominance and psychopathy: A response to Lilienfeld et al. Personality Disorders: Theory, Research, and Treatment, 3, 341-353. http://dx.doi.org/10.1037/a0028296.

Megías, A., Gómezleal, R., Gutiérrezcobo, M. J., Cabello, R., \& Fernándezberrocal, P. (2018). The relationship between trait psychopathy and emotional intelligence: A metaanalytic review. Neuroscience \& Biobehavioral Reviews, 84,198-203. http://dx.doi.org/10.1016/j.neubiorev.2017.12.003.

Miller, J. D., \& Lynam, D. R. (2015). Psychopathy and personality: Advances and debates. Journal of Personality, 83, 585-592. http://dx.doi.org/10.1111/jopy.12145.

Muñoz, L. C., \& Frick, P. J. (2007). The reliability, stability, and predictive utility of the selfreport version of the Antisocial Process Screening Device. Scandinavian Journal of Psychology, 48(4), 299-312. https://doi.org/10.1111/j.1467-9450.2007.00560.x

Muthén, L. K., \& Muthén, B. O. (1998-2015). Mplus user's guide (7th ed.). Los Angeles, CA: Author.

Neumann, C. S., Hare, R. D., \& Newman, J. P. (2007). The super-ordinate nature of the Psychopathy Checklist-Revised. Journal of Personality Disorders, 21, 102-117. http://dx.doi.org/10.1521/pedi.2007.21.2.102.

Neumann, C. S., Hare, R. D., \& Pardini, D. A. (2015). Antisociality and the construct of psychopathy: Data from across the globe. Journal of Personality, 83, 678-692. http://dx.doi.org/10.1111/jopy.12127.

Neumann, C. S., Johansson, P. T., \& Hare, R. D. (2013). The Psychopathy Checklist-Revised (PCL-R), low anxiety, and fearlessness: A structural equation modeling 
analysis. Personality Disorders: Theory, Research, and Treatment, 4, 129-137. http://dx.doi.org/ 10.1037/a0027886.

Neumann, C. S., Kosson, D. S., Forth, A. E., \& Hare, R. D. (2006). Factor structure of the Hare Psychopathy Checklist: Youth Version (PCL: YV) in incarcerated adolescents. Psychological Assessment, 18, 142-154. http://dx.doi.org/10.1037/10403590.18.2.142.

Neumann, C. S., Schmitt, D. S., Carter, R., Embley, I., \& Hare, R. D. (2012). Psychopathic traits in females and males across the globe. Behavioral sciences \& the law, 30, 557574. http://dx.doi.org/10.1002/bsl.2038.

Neumann, C., Wampler, M., Taylor, J., Blonigen, D. M., \& Iacono, W. G. (2011). Stability and invariance of psychopathic traits from late adolescence to young adulthood. Journal of Research in Personality, 45, 145-152. http://dx.doi.org/ 10.1016/j.jrp.2010.12.003.

Pechorro, P., Maroco, J., Poiares, C., \& Vieira, R. X. (2013). Validation of the Portuguese version of the Antisocial Process Screening Device-Self-Report with a focus on delinquent behavior and behavior problems. International Journal of Offender Therapy and Comparative Criminology, 57, 112-126.

Quay, H. C. (1986). A critical analysis of the DSM-III as a taxonomy of psychopathology in childhood and adolescence. In T. Millon, G. L. Klerman, (Eds.), Contemporary directions in psychopathology: Toward the DSM-IV (pp. 151-165). New York, NY: Guilford Press.

Raine, A., Dodge, K., Loeber, R., Gatzke-Kopp, L., Lynam, D., Reynolds, C., \& Liu, J. (2006). The Reactive-Proactive Aggression Questionnaire: Differential correlates of reactive and proactive aggression in adolescent boys. Aggressive Behavior, 32, 159-171. http://dx.doi.org/10.1002/ab.20115. 
Ray, J. V., Frick, P. J., Thornton, L. C., Steinberg, L., \& Cauffman, E. (2016). Positive and negative item wording and its influence on the assessment of callous-unemotional traits. Psychological Assessment, 28, 394-404. http://dx.doi.org/10.1037/pas0000183.

Reise, S. P. (2012). The rediscovery of bifactor measurement models. Multivariate Behavioral Research, 47, 667-696. http://dx.doi.org/10.1080/00273171.2012.715555.

Reise, S. P., Bonifay, W. E., \& Haviland, M. G. (2013). Scoring and modeling psychological measures in the presence of multidimensionality. Journal of Personality Assessment, 95, 129-140. http://dx.doi.org/10.1080/00223891.2012.725437.

Rodriguez, A., Reise, S. P., \& Haviland, M. G. (2016). Applying bifactor statistical indices in the evaluation of psychological measures. Journal of Personality Assessment, 98, 223237. http://dx.doi.org/10.1080/00223891.2015.1089249.

Rogers, R. (2001). Diagnostic and structured interviewing ( $2^{\text {nd }}$ ed.). Odessa, FL: PAR.

Rutter, M. (2005). Commentary: What is the meaning and utility of the psychopathy concept? Journal of Abnormal Child Psychology, 33, 499-503.

Salekin, R. T. (2008). Psychopathy and recidivism from mid-adolescence to young adulthood: Cumulating legal problems and limiting life opportunities. Journal of Abnormal Psychology, 17, 386-395. http://dx.doi.org/10.1037/0021-843X.117.2.386.

Salekin, R. T. (2010). Psychopathy in children and adolescents: The road ahead. In R. T. Salekin \& D. R. Lynam (Eds.), Handbook of child and adolescent psychopathy (pp. 401-419). New York: Guilford.

Salekin, R. T. (2016a). Psychopathy in childhood: Toward better informing the DSM-5 and ICD-11 conduct disorder specifiers. Personality Disorders: Theory, Research, and Treatment, 7, 180-191. http://dx.doi.org/10.1037/per0000150. 
Salekin, R. T. (2016b). Psychopathy in childhood: Why should we care about grandiosemanipulative and daring-impulsive traits? British Journal of Psychiatry, 209, 189-191. https://doi.org/10.1192/bjp.bp.115.179051

Salekin, R. T. (2017). Research review: What do we know about psychopathic traits in children? Journal of Child Psychology and Psychiatry, 58, 1180-1200. http://dx.doi.org/10.1111/jcpp.12738.

Salekin, R. T., Andershed, H., Batky, B. D., \& Bontemps, A. P. (2018). Are callous unemotional (CU) traits enough? Journal of Psychopathology and Behavioral Assessment, 40, 1-5. http://dx.doi.org/10.1007/s10862-018-9663-9.

Salekin, R. T., Andershed, H., \& Clark, A. P. (2018). Psychopathy in children and adolescents: Assessment and critical questions regarding conceptualization. In C. J. Patrick (Ed.), Handbook of psychopathy (2 ${ }^{\text {nd }}$ ed.), (pp. 479-508).

Salekin, R. T., \& Hare, R. D. (2016). Proposed specifiers for conduct disorder (PSCD) scale. Unpublished test.

Salekin, R. T., \& Lynam, D. R. (2010). Handbook of child and adolescent psychopathy. New York, NY: Guilford Press.

Salekin, R. T., Neumann, C.S., Leistico, A.R., \& Zalot, A.A. (2004). Psychopathy in youth and intelligence: An investigation of Cleckley's hypothesis. Journal of Clinical Child and Adolescent Psychology, 33, 731-742. http://dx.doi.org/10.1207/s15374424jccp3304_8.

Sharp, C., Steinberg, L., Temple, J., \& Newlin, E. (2014). An 11-item measure to assess borderline traits in adolescents: Refinement of the BPFSC using IRT. Personality Disorders: Theory, Research, and Treatment, 5, 70-78. http://dx.doi.org/10.1037/per0000057. 
Somma, A., Andershed, H., Borroni, S., \& Fossati, A. (2016). The validity of the child problematic trait inventory in 6-12 year old Italian children: Further support and issues of consistency across different sources of information and different samples. Journal of Psychopathology and Behavioral Assessment, 38, 350-372. http://dx.doi.org/10.1007/s10862-015-9528-4.

Somma, A., Andershed, H., Borroni, S., Salekin, R. T., \& Fossati, A. (2018). Psychopathic personality traits in relation to self-report delinquency in adolescence: Should we mind about interaction effects? Journal of Psychopathology and Behavioral Assessment, 40, 69-78. https://doi.org/10.1007/s10862-018-9658-6

Spitzer, R. L., Kroenke, K., Williams, J. B. W., \& Löwe, B. (2006). A brief measure for assessing generalized anxiety disorder: The GAD-7. Archives of Internal Medicine, 166, 1092-1097. http://dx.doi.org/10.1001/archinte.166.10.1092.

Tavakol, M., \& Dennick, R. (2011). Making sense of Cronbach's alpha. International Journal of Medical Education, 2, 53-55. http://dx.doi.org/10.5116/ijme.4dfb.8dfd.

Tuvblad, C., Fanti, K. A., Andershed, H., Colins, O. F., \& Larsson, H. (2017). Psychopathic personality traits in 5 year old twins: The importance of genetic and shared environmental influences. European Child \& Adolescent Psychiatry, 26, 469-479. http://dx.doi.org/10.1007/s00787-016-0899-1.

Vahl, P., Colins, O., Markus, M., Lodewijkcs, H., Doreleijers, T., \& Vermeiren, R. (2014). Psychopathic-like traits in detained male adolescents: The usefulness of self-report outside a research context. European Child \& Adolescent Psychiatry, 23, 691-699. van Baardewijk, Y., Andershed, H., Stegge, H., Nilsson, K.W., Scholte, E., \& Vermeiren, R. (2010). Development and tests of short versions of the youth psychopathic traits inventory and the youth psychopathic traits inventory-child version. European Journal of Psychological Assessment, 26, 122-128. 
van Baardewijk, Y., Stegge, H., Bushman, B.J., \& Vermeiren, R. (2009). Psychopathic traits, victim distress and aggression in children. Journal of Child Psychology and Psychiatry, 50, 718-725. http://dx.doi.org/10.1111/j.1469-7610.2008.02023.x.

Verona, E., Sadeh, N., \& Javdani, S. (2010). The influences of gender and culture on child and adolescent psychopathy. In R. T. Salekin \& D. R. Lynam (Eds.), Handbook of child and adolescent psychopathy (pp. 317-342). New York: Guilford.

Vitacco, M. J., Neumann, C. S., Caldwell, M. F., Leistico, A. M., \& Van Rybroek, G. J. (2006). Testing factor models of the Psychopathy Checklist: Youth Version and their association with instrumental aggression. Journal of Personality Assessment, 87, 74-83. http://dx.doi.org/10.1207/s15327752jpa8701_06.

Vitacco, M. J., Rogers, R., \& Neumann, C. S. (2003). The Antisocial Process Screening Device: An examination of its construct and criterion-related validity. Assessment,10, 143-150. http://dx.doi.org/10.1177/1073191103010002005.

Waller, R., Gardner, F., Hyde, L.W., Shaw, D.S., Dishion, T.J., \& Wilson, M.N. (2012). Do harsh and positive parenting predict parent reports of deceitful-callous behavior in early childhood? Journal of Child Psychology and Psychiatry, 53, 946-953. http://dx.doi.org/10.1111/j.1469-7610.2012.02550.x.

Walton, K. E., Roberts, B. W., Krueger, R. F., Blonigen, D. M., \& Hicks, B. M. (2008). Capturing abnormal personality with normal personality inventories: An item response theory approach. Journal of Personality, 76, 1623-1648. http://dx.doi.org/10.1111/j.1467-6494.2008.00533.x.

Wang, M.-C., Colins, O. F., Deng, Q., Andershed, H., Deng, J., \& Ye, H. (2017). Psychometric properties of the original and shortened version of the Youth Psychopathic Traits Inventory among Chinese adolescents. Journal of Psychopathology and Behavioral Assessment, 39, 620-634. http://dx.doi.org/10.1007/s10862-017-9619-5. 
Wang, M.-C., Colins, O. F., Deng, Q., Deng, J., Huang, Y., \& Andershed, H. (2018). The Child Problematic Traits Inventory in China: A multiple informant-based validation study. Psychological Assessment, 30, 956-966. http://dx.doi.org/10.1037/pas0000545.

Wang, M.-C., Deng, Q., Armour, C., Bi, X., \& Zeng, H. (2015). The psychometric properties and factor structure of the Antisocial Process Screening Device self-report version in Chinese adolescents. Journal of Psychopathology and Behavioral Assessment, 37, 553562. http://dx.doi.org/10.1007/s10862-015-9486-x.

Wang, M.-C., Gao, Y., Deng, J., Lai, H., Deng, Q., \& Armour, C. (2017). The factor structure and construct validity of the Inventory of Callous-Unemotional Traits in Chinese undergraduate students. PLoS ONE, 12, e0189003. http://dx.doi.org/10.1371/journal.pone.0189003.

Wang, M.-C., Shou, Y., Liang, J., Lai, H., Zeng, H., Chen, L., \& Gao, Y. (2019). Further validation of the Inventory of Callous-Unemotional Traits in Chinese: Cross-informants invariance and longitudinal invariance. Assessment. Advance online publication. http://dx.doi.org/10.1177/1073191119845052.

White, S. F., Cruise, K. R., \& Frick, P. J. (2009). Differential correlates to self-report and parent-report of callous-unemotional traits in a sample of juvenile sexual offenders. Behavioral Sciences and the Law, 27(6), 910-928. https://doi.org/10.1002/bsl.911 Zhang, X., Shou, Y., Wang, M.-C., Zhong, C., Luo, J., Gao, Y., \& Yang, W. (2019). Assessing callous-unemotional traits in Chinese detained boys: Factor structure and construct validity of the Inventory of Callous-Unemotional Traits. Frontiers in Psychology, 10, 1841. http://dx.doi.org/10.3389/fpsyg.2019.01841.

Zinbarg, R., Yovel, I., Revelle,W., \& McDonald, R. P. (2006). Estimating generalizability to a latent variable common to all of a scale's indicators: A comparison of estimators for wh. Applied Psychological Measurement, 30, 121-144. 
Zwaanswijk, W., Veen, V. C., \& Vedder, P. (2017). The Youth Psychopathic Traits

Inventory: A bifactor model, dimensionality, and measurement invariance. Assessment, 24, 932-944. https:// dx.doi.org/10.1177/1073191116632340. 
Table 1

Descriptive Statistics for the Proposed Specifiers for Conduct Disorder Scale $(n=1,683)$

\begin{tabular}{|c|c|c|c|c|c|c|}
\hline Item & Min & Max & $M$ & $S D$ & $S K$ & $K U$ \\
\hline PSCD 1 - I can turn on the charm in any situation & 0 & 2 & .69 & .60 & .23 & -.62 \\
\hline PSCD 2 - I am a very important person & 0 & 2 & .86 & .68 & 19 & -.86 \\
\hline PSCD 3 - I am very good at most things I do & 0 & 2 & 1.14 & .63 & -.12 & -.55 \\
\hline PSCD 4 - Lying is easy for me & 0 & 2 & .54 & .66 & .82 & -.42 \\
\hline PSCD 5 - I take advantage of others & 0 & 2 & .30 & .51 & 1.48 & 1.26 \\
\hline PSCD 6 - I am a natural storyteller & 0 & 2 & .65 & .71 & .62 & -.83 \\
\hline $\begin{array}{l}\text { PSCD } 7 \text { - I don't waste time thinking about how I may } \\
\text { have hurt others }\end{array}$ & 0 & 2 & .29 & .51 & 1.49 & 1.29 \\
\hline $\begin{array}{l}\text { PSCD } 8 \text { - I can turn and walk away from someone who } \\
\text { is hurt }\end{array}$ & 0 & 2 & .40 & .60 & 1.19 & .38 \\
\hline $\begin{array}{l}\text { PSCD } 9 \text { - When people are happy or upset I do not } \\
\text { seem to care }\end{array}$ & 0 & 2 & .22 & .47 & 2.06 & 3.49 \\
\hline PSCD 10 - I like it when others are afraid of me & 0 & 2 & .22 & .51 & 2.26 & 4.25 \\
\hline $\begin{array}{l}\text { PSCD } 11 \text { - Some people consider me to be a mean } \\
\text { person }\end{array}$ & 0 & 2 & .38 & .58 & 1.26 & .59 \\
\hline PSCD 12 - I rarely feel guilt or remorse & 0 & 2 & .40 & .60 & 1.20 & .41 \\
\hline PSCD 13 - I am daring & 0 & 2 & .90 & .67 & .12 & -.79 \\
\hline PSCD 14 - I like a lot of change or adventure & 0 & 2 & 1.07 & .74 & -.11 & -1.15 \\
\hline PSCD 15 - I get a thrill out of doing risky things & 0 & 2 & .24 & .50 & 2.03 & 3.33 \\
\hline PSCD 16 - I feel like I need a lot of stimulation & 0 & 2 & .38 & .61 & 1.37 & .76 \\
\hline PSCD 17 - I like to live in the moment & 0 & 2 & 1.43 & .67 & -.76 & -.55 \\
\hline PSCD 18 - Some people think I am reckless & 0 & 2 & .65 & .70 & 60 & -.80 \\
\hline PSCD 19 - I have stolen things & 0 & 2 & .37 & .64 & 1.49 & .93 \\
\hline $\begin{array}{l}\text { PSCD } 20 \text { - I have engaged in physical aggression } \\
\text { against animals or people }\end{array}$ & 0 & 2 & .67 & .75 & 62 & -.96 \\
\hline PSCD 21 - I have destroyed property & 0 & 2 & .46 & .67 & 1.12 & .02 \\
\hline PSCD 22 - I break (violate) a lot of rules & 0 & 2 & .49 & .64 & .93 & -.22 \\
\hline PSCD 23 - I started breaking rules before the age of 10 & 0 & 2 & .19 & .46 & 2.46 & 5.41 \\
\hline $\begin{array}{l}\text { PSCD } 24 \text { - I can be argumentative and defiant } \\
\text { (oppositional) }\end{array}$ & 0 & 2 & .39 & .60 & 1.28 & .59 \\
\hline
\end{tabular}


Table 2

The Standardized Factor Loadings for the PSCD Bifactor Model

\begin{tabular}{|c|c|c|c|c|c|}
\hline Item & GM & $\mathrm{CU}$ & DI & $\mathrm{CD}$ & Psychopathy \\
\hline PSCD-1 & $.68^{* * * *}$ & & & & $.17^{* * * *}$ \\
\hline PSCD-2 & $.67^{* * * *}$ & & & & $.10^{* *}$ \\
\hline PSCD-3 & $.50^{* * * *}$ & & & & $.13^{* * * *}$ \\
\hline PSCD-4 & .02 & & & & $.70^{* * * *}$ \\
\hline PSCD-5 & -.02 & & & & $.58^{* * *}$ \\
\hline PSCD-6 & $.12^{* * * *}$ & & & & $.58^{* * * *}$ \\
\hline PSCD-7 & & $.61^{* * * *}$ & & & $.31^{* * *}$ \\
\hline PSCD-8 & & $.37^{* * * *}$ & & & $.33^{* * *}$ \\
\hline PSCD-9 & & $.68^{* * * *}$ & & & $.39^{* * * *}$ \\
\hline PSCD-10 & & $.17^{* * * *}$ & & & $.49^{* * * *}$ \\
\hline PSCD-11 & & .05 & & & $.39^{* * * *}$ \\
\hline PSCD-12 & & $.30^{* * * *}$ & & & $.16^{* * * *}$ \\
\hline PSCD-13 & & & $.58^{* * *}$ & & $.23^{* * * *}$ \\
\hline PSCD-14 & & & $.70^{* * *}$ & & $.34^{* * * *}$ \\
\hline PSCD-15 & & & $.48^{* * *}$ & & $.65^{* * *}$ \\
\hline PSCD-16 & & & $.39^{* * *}$ & & $.54^{* * * *}$ \\
\hline PSCD-18 & & & .02 & & $.53^{* * *}$ \\
\hline PSCD-19 & & & & $.37^{* * * *}$ & $.51^{* * * *}$ \\
\hline PSCD-20 & & & & $.51^{* * * *}$ & $.57^{* * * *}$ \\
\hline PSCD-21 & & & & $.57^{* * * *}$ & $.52^{* * * *}$ \\
\hline PSCD-22 & & & & .08 & $.63^{* * * *}$ \\
\hline PSCD-23 & & & & .09 & $.55^{* * * *}$ \\
\hline PSCD-24 & & & & -.08 & $.65^{* * *}$ \\
\hline$\omega_{\mathrm{H}} / \omega_{\mathrm{HS}}$ & .31 & .36 & .37 & .14 & .77 \\
\hline$\omega / \omega_{\mathrm{Sj}}$ & .71 & .69 & .79 & .81 & .90 \\
\hline $\mathrm{ECV}$ & .13 & .05 & .14 & .09 & .59 \\
\hline
\end{tabular}

Note. PSCD $=$ the Proposed Specifiers for Conduct Disorder Scale; GM = Grandiose-

Manipulative; $\mathrm{CU}=$ Callous-Uncaring; $\mathrm{DI}=$ Daring-Impulsive $; \mathrm{CD}=$ Conduct Disorder; $\mathrm{GF}$ $=$ General Factor. ${ }^{*} p<.05 ;{ }^{* *} p<.01 ;{ }^{* * *} p<.001$. 
Table 3

Correlations between the PSCD Scores and APSD, ICU, YPI, YSR, RPQ, GAD, and PHQ Measures

\begin{tabular}{|c|c|c|c|c|c|}
\hline Measure & GM & $\mathrm{CU}$ & DI & $\mathrm{CD}$ & PSCD total \\
\hline $\mathrm{CU}$ & $.332^{* * *}$ & 1 & & & \\
\hline DI & $.393^{* * * *}$ & $.305^{* * *}$ & 1 & & \\
\hline $\mathrm{CD}$ & $.306^{* * *}$ & $.419^{* * *}$ & $.367^{* * * *}$ & 1 & \\
\hline PSCD total & $.720^{* * * *}$ & $.673^{* * *}$ & $.747^{* * * *}$ & $.730^{* * *}$ & 1 \\
\hline Nar & $.466^{* * *}$ & $.451^{* * *}$ & $.304^{* * * *}$ & $.440^{* * *}$ & $.575^{* * *}$ \\
\hline $\operatorname{Imp}$ & $.357^{* * * *}$ & $.343^{* * * *}$ & $.482^{* * * *}$ & $.412^{* * *}$ & $.585^{* * *}$ \\
\hline $\mathrm{CU}$ & .003 & $.225^{* * *}$ & .011 & $.144^{* *}$ & $.126^{* *}$ \\
\hline ASO & $.190^{* * *}$ & $.218^{* * *}$ & $.212^{* * *}$ & $.297^{* * *}$ & $.333^{* * *}$ \\
\hline APSD total & $.403^{* * *}$ & $.491^{* * *}$ & $.421^{* * *}$ & $.497^{* * *}$ & $.647^{* * *}$ \\
\hline $\mathrm{CA}$ & $.289^{* * *}$ & $.479^{* * * *}$ & $.258^{* * * *}$ & $.392^{* * *}$ & $.503^{* * *}$ \\
\hline UC & -.031 & $.295^{* * *}$ & -.064 & $.112^{*}$ & .089 \\
\hline ICU total & $.132^{* *}$ & $.478^{* * *}$ & $.095^{*}$ & $.296^{* * *}$ & $.335^{* * * *}$ \\
\hline GM & $.475^{* * *}$ & $.314^{* * *}$ & $.339^{* * * *}$ & $.341^{* * *}$ & $.514^{* * *}$ \\
\hline $\mathrm{CU}$ & $.254^{* * *}$ & $.328^{* * *}$ & $.337^{* * * *}$ & $.293^{* * *}$ & $.428^{* * * *}$ \\
\hline II & $.155^{* *}$ & $.206^{* * *}$ & $.368^{* * * *}$ & $.363^{* * *}$ & $.393^{* * *}$ \\
\hline YPI total & $.380^{* * *}$ & $.396^{* * *}$ & $.464^{* * * *}$ & $.445^{* * *}$ & $.595^{* * *}$ \\
\hline RB & $.288^{* * * *}$ & $.372^{* * * *}$ & $.301^{* * * *}$ & $.544^{* * *}$ & $.523^{* * * *}$ \\
\hline AGG & $.313^{* * * *}$ & $.411^{* * * *}$ & $.395^{* * *}$ & $.610^{* * *}$ & $.607^{* * * *}$ \\
\hline YSR total & $.334^{* * *}$ & $.439^{* * * *}$ & $.403^{* * * *}$ & $.652^{* * *}$ & $.640^{* * * *}$ \\
\hline RA & $.292^{* * *}$ & $.229^{* * * *}$ & $.344^{* * * *}$ & $.400^{* * *}$ & $.461^{* * * *}$ \\
\hline PA & $.309^{* * *}$ & $.327^{* * * *}$ & $.319^{* * * *}$ & $.401^{* * *}$ & $.462^{* * * *}$ \\
\hline RPQ total & $.352^{* * *}$ & $.313^{* * *}$ & $.412^{* * * *}$ & $.482^{* * *}$ & $.554^{* * *}$ \\
\hline GAD-total & .035 & $.156^{* * *}$ & .068 & $.220^{* * * *}$ & $.168^{* * *}$ \\
\hline PHQ-total & .033 & $.187^{* * * *}$ & $.123^{* *}$ & $.269^{* * *}$ & $.213^{* * * *}$ \\
\hline
\end{tabular}

Notes. PSCD $=$ the Proposed Specifiers for Conduct Disorder Scale; GM = GrandioseManipulative $; \mathrm{CU}=$ Callous-Uncaring; $\mathrm{DI}=$ Daring-Impulsive $; \mathrm{CD}=$ Conduct Disorder; APSD = Antisocial Process Screening Device; Nar = Narcissistic; $\operatorname{Imp}=$ Impulsive; $\mathrm{CU}=$ Callous-Unemotional; ASO = Asocial behavior; ICU $=$ the Inventory of CallousUnemotional Traits short version; $\mathrm{CA}=$ Callousness; $\mathrm{UC}=$ Uncaring; YPI = Youth Psychopathic Traits Inventory short version; GM = Grandiose-Manipulative; $\mathrm{CU}=$ CallousUnemotional; II = Impulsive-Irresponsible; YSR = Youth-Self Report; RB = Rule Breaking behavior; $\mathrm{AGG}=$ Aggressive behavior; $\mathrm{RPQ}=$ the Reactive-Proactive Aggression Questionnaire short form; RA = Reactive Aggression; PA = Proactive Aggression; GAD = the Generalized Anxiety Disorder; PHQ = the Patient Health Questionnaire. ${ }^{*} p<.05 ;^{* *} p<.01{ }^{* * *} p<.001$. 
Table 4

Correlations between the Psychopathy Scales Subscales for the PSCD, YPI, and APSD

\begin{tabular}{|c|c|c|c|c|c|c|c|c|c|c|c|c|c|c|c|}
\hline \multirow[b]{2}{*}{ Measure } & \multicolumn{3}{|c|}{ PSCD-24 } & \multicolumn{3}{|c|}{ PSCD-23 } & \multicolumn{3}{|c|}{ PSCD-13 } & \multicolumn{3}{|c|}{$\underline{\text { YPI }}$} & \multicolumn{3}{|c|}{$\underline{\mathrm{APSD}}$} \\
\hline & GM & $\mathrm{CU}$ & DI & GM & $\mathrm{CU}$ & DI & GM & $\mathrm{CU}$ & $\mathrm{DI}$ & GD & $\mathrm{CU}$ & INS & Nar & $\mathrm{CU}$ & Imp \\
\hline \multicolumn{16}{|l|}{ PSCD-24 } \\
\hline GM & 1.00 & & & & & & & & & & & & & & \\
\hline $\mathrm{CU}$ & .332 & 1.00 & & & & & & & & & & & & & \\
\hline DI & .393 & .305 & 1.00 & & & & & & & & & & & & \\
\hline \multicolumn{16}{|l|}{ PSCD-23 } \\
\hline GM & 1.00 & .332 & .393 & 1.00 & & & & & & & & & & & \\
\hline $\mathrm{CU}$ & .332 & 1.00 & .305 & .332 & 1.00 & & & & & & & & & & \\
\hline DI & .382 & .316 & .953 & .382 & .316 & 1.00 & & & & & & & & & \\
\hline \multicolumn{16}{|l|}{ PSCD-13 } \\
\hline GM & .748 & .352 & .323 & .748 & .352 & .335 & 1.00 & & & & & & & & \\
\hline $\mathrm{CU}$ & .270 & .803 & .261 & .270 & .803 & .277 & .298 & 1.00 & & & & & & & \\
\hline DI & .320 & .223 & .856 & .320 & .223 & .898 & .216 & .185 & 1.00 & & & & & & \\
\hline \multicolumn{16}{|l|}{ YPI } \\
\hline GD & .475 & .314 & .339 & .475 & .314 & .341 & .410 & .287 & .295 & 1.00 & & & & & \\
\hline $\mathrm{CU}$ & .254 & .328 & .337 & .254 & .328 & .325 & .232 & .275 & .280 & .428 & 1.00 & & & & \\
\hline IMS & .155 & .206 & .368 & .155 & .206 & .390 & .264 & .205 & .212 & .201 & .315 & 1.00 & & & \\
\hline \multicolumn{16}{|l|}{ APSD } \\
\hline Nar & .466 & .451 & .304 & .466 & .451 & .335 & .513 & .356 & .229 & .438 & .284 & .214 & 1.00 & & \\
\hline $\mathrm{CU}$ & .003 & .225 & .011 & .003 & .225 & .042 & .105 & .221 & .023 & .055 & .059 & .052 & .120 & 1.00 & \\
\hline Imp & .357 & .343 & .482 & .357 & .343 & .526 & .410 & .299 & .423 & .274 & .258 & .469 & .458 & .079 & 1.00 \\
\hline
\end{tabular}

Note. PSCD-24 = the full 24-item of the Proposed Specifiers for Conduct Disorder Scale; PSCD-23 = the 23-item of the Proposed Specifiers for Conduct

Disorder Scale; PSCD-13 = the shorter 13-item of the Proposed Specifiers for Conduct Disorder Scale; GM = Grandiose-Manipulative; CU = Callous-

Uncaring; DI = Daring-Impulsive; CD = Conduct Disorder; YPI = Youth Psychopathic Traits Inventory short version; GD = Grandiose-Deceitful; CU =

Callous-Unemotional; INS = Impulsivity-need for stimulation; APSD = Antisocial Process Screening Device; Nar $=$ Narcissistic; $\mathrm{CU}=\mathrm{Callous-Unemotional}$;

Imp= Impulsive. The bold values were the monotrait-heteromethod coefficients. 
Figure 1

Standardized parameters for the 13-item four-factor PSCD Model

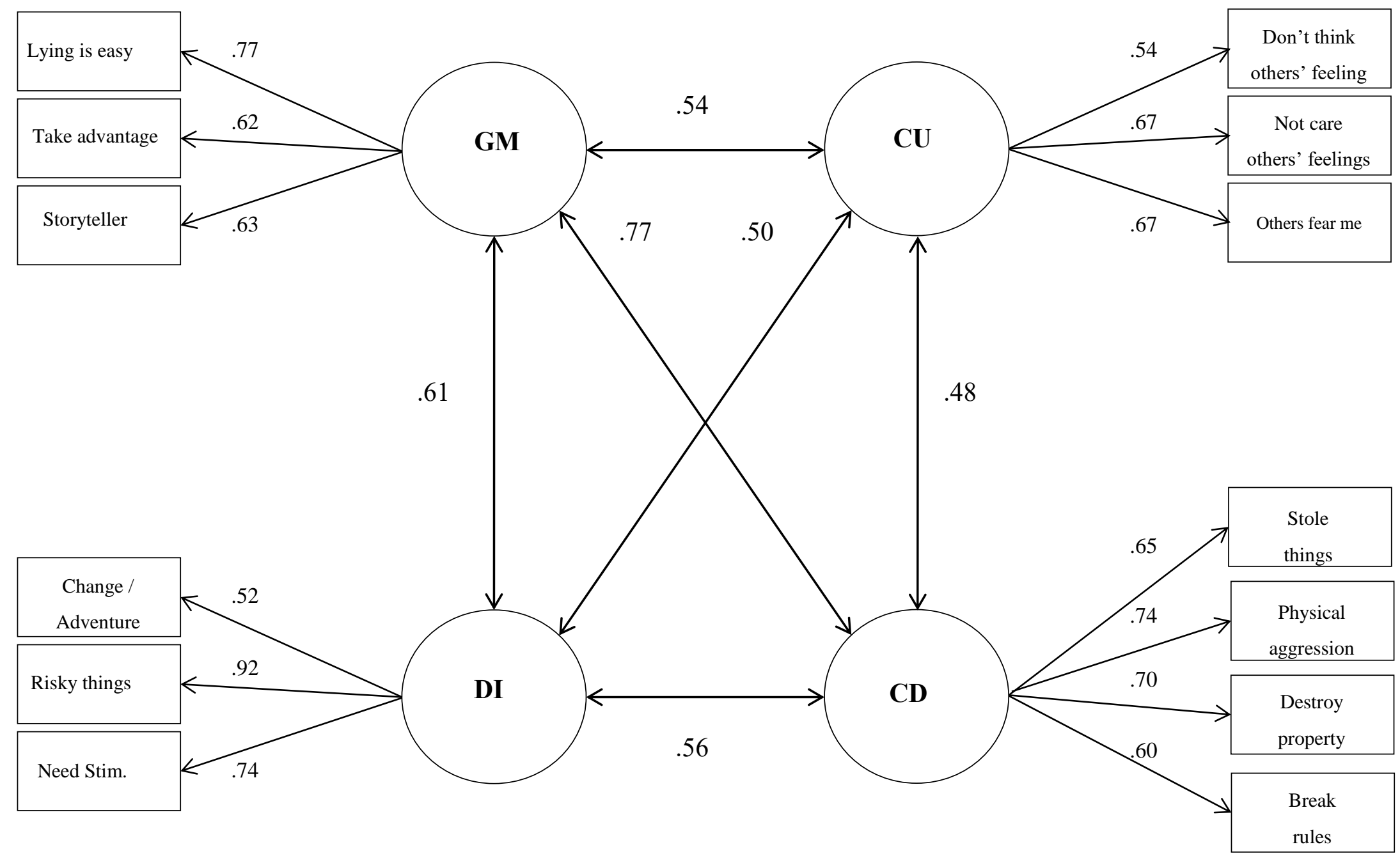


Figure 2

Standardized parameters (loadings and b2 thresholds) by sex
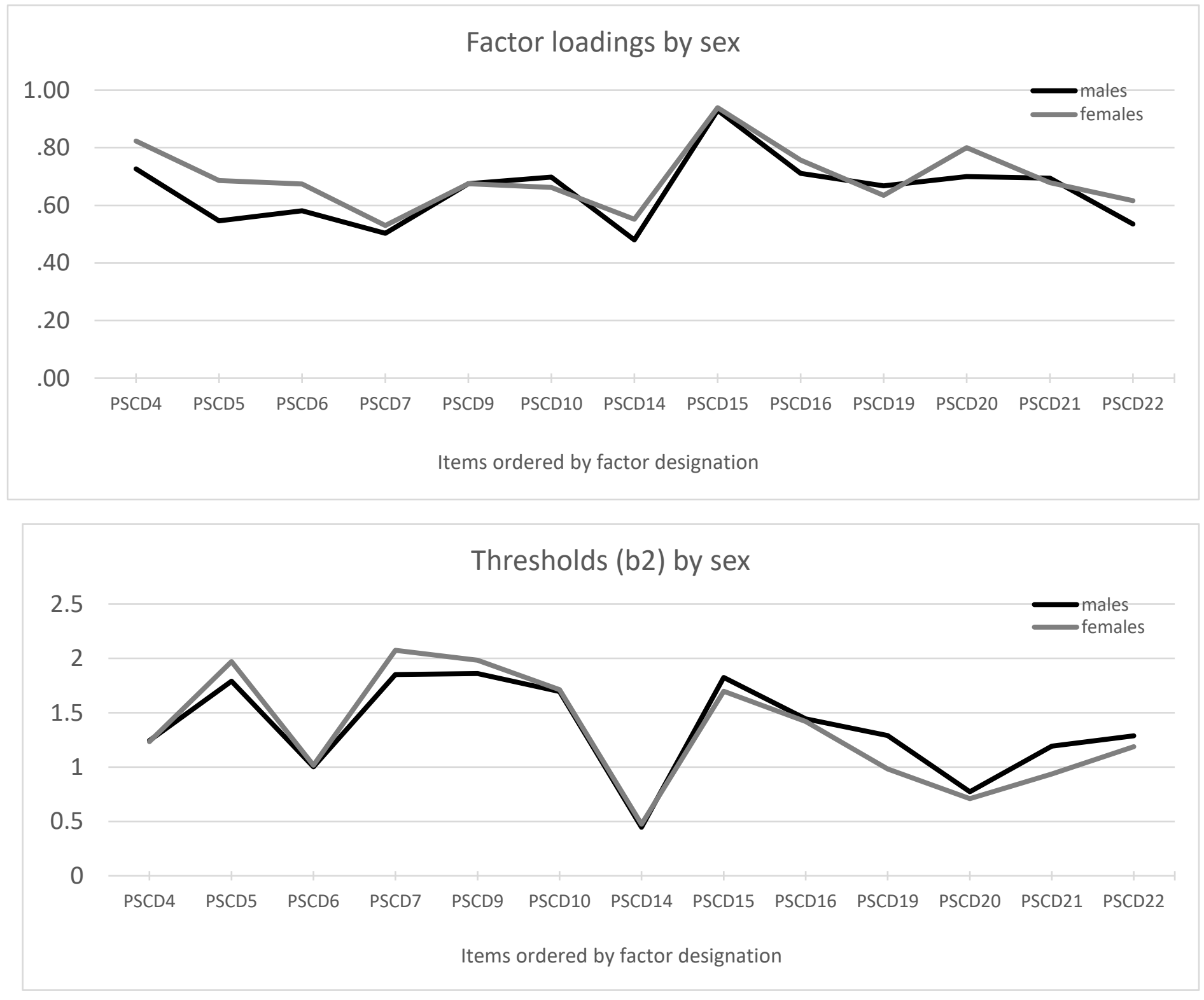